\title{
Seasonal Plasticity of Precise Spike Timing in the Avian Auditory System
}

\author{
(1D) Melissa L. Caras, ${ }^{1,2}$ Kamal Sen, ${ }^{7,8}$ Edwin W Rubel, ${ }^{2,3,4,5}$ and Eliot A. Brenowitz ${ }^{2,3,6}$ \\ ${ }^{1}$ Neurobiology and Behavior Graduate Program, ${ }^{2}$ Virginia Merrill Bloedel Hearing Research Center, Departments of ${ }^{3}$ Psychology, ${ }^{4}$ Otolaryngology-HNS, \\ ${ }^{5}$ Physiology and Biophysics, and ${ }^{6}$ Biology, University of Washington, Seattle, Washington 98195, and ${ }^{7}$ Hearing Research Center and ${ }^{8}$ Department of \\ Biomedical Engineering, Boston University, Boston, Massachusetts 02215
}

Vertebrate audition is a dynamic process, capable of exhibiting both short- and long-term adaptations to varying listening conditions. Precise spike timing has long been known to play an important role in auditory encoding, but its role in sensory plasticity remains largely unexplored. We addressed this issue in Gambel's white-crowned sparrow (Zonotrichia leucophrys gambelii), a songbird that shows pronounced seasonal fluctuations in circulating levels of sex-steroid hormones, which are known to be potent neuromodulators of auditory function. We recorded extracellular single-unit activity in the auditory forebrain of males and females under different breeding conditions and used a computational approach to explore two potential strategies for the neural discrimination of sound level: one based on spike counts and one based on spike timing reliability. We report that breeding condition has robust sex-specific effects on spike timing. Specifically, in females, breeding condition increases the proportion of cells that rely solely on spike timing information and increases the temporal resolution required for optimal intensity encoding. Furthermore, in a functionally distinct subset of cells that are particularly well suited for amplitude encoding, female breeding condition enhances spike timing-based discrimination accuracy. No effects of breeding condition were observed in males. Our results suggest that high-resolution temporal discharge patterns may provide a plastic neural substrate for sensory coding.

Key words: auditory; hormone; neural coding; plasticity; seasonal; spike timing

\section{Introduction}

Neural codes can take two basic forms: count-based (i.e., how many spikes occur) and timing-based (i.e., when spikes occur) (Theunissen and Miller, 1995; Eggermont, 1998; Huetz et al., 2011; Gaucher et al., 2013). Despite decades of work establishing the importance of precise spike timing in the auditory nerve (Kiang, 1965; Rose et al., 1967; Young and Sachs, 1979), the role of temporal coding has only recently been explored in more central regions: midbrain (Holmstrom et al., 2010; Woolley and Portfors, 2013), thalamus (Huetz et al., 2009), and forebrain (Narayan et al., 2006; Schnupp et al., 2006; Engineer et al., 2008; Kayser et al., 2010).

Auditory encoding is dynamic, modulated by arousal state (Dave et al., 1998; Cardin and Schmidt, 2003; Huetz et al., 2009), behavioral experience (Bakin and Weinberger, 1990; Recanzone

Received Aug. 14, 2014; revised Jan. 9, 2015; accepted Jan. 16, 2015.

Author contributions: M.L.C., E.W.R., and E.A.B. designed research; M.L.C. performed research; M.L.C. and K.S. analyzed data; M.L.C., K.S., E.W.R., and E.A.B. wrote the paper.

This work was supported by National Institutes of Health Grants F31DC010938 to M.L.C., R01DC003829 to E.W.R., and P30DC004661 and R01MH53032 to E.A.B., the Seattle Chapter of Achievement Rewards for College Scientists Foundation, and the Washington Research Foundation. We thank Brandon Warren, David Schneider, and Sarah M. N. Woolley for technical assistance; Christine Portfors for insightful data analysis suggestions; and members of the E.A.B. and E.W.R. laboratories for constructive discussion and support.

The authors declare no competing financial interests.

Correspondence should be addressed to Dr. Melissa L. Caras, Center for Neural Science, New York University, 4 Washington Place, Room 809, New York, NY 10012. E-mail: caras@nyu.edu.

DOI:10.1523/JNEUROSCI.3407-14.2015

Copyright $\odot 2015$ the authors $\quad 0270-6474 / 15 / 353431-15 \$ 15.00 / 0$ et al., 1993; Polley et al., 2006), task engagement (Fritz et al., 2003, 2005; Niwa et al., 2012; Yin et al., 2014), and environmental cues (Walkowiak, 1980; Hillery, 1984; Del Negro and Edeline, 2002; Sisneros and Bass, 2003; Del Negro et al., 2005). Sex-steroid hormones are effective regulators of neural function (Caras, 2013), capable of rapid modulations via brain-derived neurosteroids (Pinaud and Tremere, 2012; Remage-Healey et al., 2013) and slower changes that correlate with hormonally mediated fluctuations in reproductive condition (Sisneros et al., 2004; Caras et al., 2010, 2012; Rohmann and Bass, 2011; Maruska et al., 2012). Investigations of the effect of sex-steroid hormones on the auditory forebrain have focused on average discharge rates (Tremere et al., 2009, 2012; Remage-Healey et al., 2010, 2012; Caras et al., 2012; Remage-Healey and Joshi, 2012); temporal coding modulations remain largely unexplored (but see Liu and Schreiner, 2007; Tremere and Pinaud, 2011).

Precise spike timing plays an important role in the encoding of sound level (Kiang, 1965; Malone et al., 2010), a fundamental aspect of auditory processing. Signal amplitude is particularly relevant during social interactions in breeding animals. For example, female frogs and birds often prefer males that produce loud vocalizations (Fellers, 1979; Arak, 1983, 1988; Gerhardt, 1987; Searcy, 1996). In addition, in some songbird species, lowintensity songs convey aggression (Searcy and Beecher, 2009; Hof and Hazlett, 2010; Akçay et al., 2011). These observations raise the possibility that signal amplitude encoding is hormonally modulated. 
Here, we addressed this issue by determining whether the sound level of a naturalistic, time-varying stimulus is better encoded by spike counts and/or spike timing, and whether this encoding is modulated by hormonal condition. We recorded song-evoked in vivo single-unit responses in the auditory forebrain of Gambel's white-crowned sparrows (Zonotrichia leucophrys gambelii), a species in which both vocal motor (Park et al., 2005; Meitzen et al., 2007a, b, 2009a, b) and auditory function (Caras et al., 2010,2012) are modulated by circulating levels of sex steroids, which fluctuate on a seasonal basis (Wingfield and Farner, 1978). We report that, in females, breeding condition selectively enhances spike timing-based discrimination and increases the temporal resolution for optimal intensity encoding.

\section{Materials and Methods}

Subjects. Adult male $(n=19)$ and female $(n=21)$ Gambel's whitecrowned sparrows were captured in eastern Washington state during autumn and spring migrations between 2007 and 2011. Birds were housed at the University of Washington in outdoor aviaries before being moved indoors. Once inside, all birds were housed in aviaries on a shortday photoperiod ( $8 \mathrm{~h}$ light:16 h dark) for at least 10 weeks to ensure sensitivity to photoperiod and hormones (Wingfield et al., 1979). Food and water were freely available. All procedures were approved by the Institutional Animal Care and Use Committee at the University of Washington, Seattle.

Hormone and photoperiod manipulations. We manipulated light and hormone levels to mimic nonbreeding and breeding conditions in the laboratory. To induce a nonbreeding state, birds (males $=10$, females $=$ 12) were housed on a short-day photoperiod. Under these conditions, gonads are regressed, plasma sex hormone levels are basal, and neural morphology and physiology are typical of the nonbreeding season (Middleton, 1965; Smith et al., 1995; Tramontin et al., 2000; Park et al., 2005; Meitzen et al., 2007a). To induce a breeding state, males $(n=9)$ and females $(n=9)$ were housed on a long day ( 20 h light: 4 h dark) photoperiod typical of their Alaskan breeding grounds. Additionally, because supplemental hormone is necessary to raise plasma hormone levels of laboratory-housed birds to physiological levels observed in the wild (Smith et al., 1995), these birds received subcutaneous hormone pellets made from Silastic tubing (i.d. $1.0 \mathrm{~mm}$; o.d. $2.0 \mathrm{~mm}$, length 12 $\mathrm{mm}$; VWR), filled with crystalline testosterone (males) or estradiol (females) (Tramontin et al., 2003; Caras et al., 2010, 2012). Birds were exposed to these conditions for a minimum of 3 weeks, a time period sufficient to induce morphological and physiological changes typical of the breeding season (Tramontin et al., 2000; Park et al., 2005; Meitzen et al., 2007a).

Electrophysiology. Methods for in vivo electrophysiology have been described previously (Caras et al., 2012). Briefly, birds were anesthetized with $25 \%$ urethane ( $6 \mu \mathrm{l} / \mathrm{g}$ body weight, Thermo Fisher Scientific) and were secured to a head holder that served as a stereotaxic device. A small craniotomy was made above the right hemisphere and a micropipette (5-19 $\mathrm{m} \Omega$ impedance) filled with $10 \%$ fluororuby (10,000 molecular weight tetramethylrhodamine dextran, Invitrogen) or $10 \%$ biontinylated dextran amine (BDA, 10,000 molecular weight, Invitrogen) in $0.9 \%$ $\mathrm{NaCl}$ was advanced into the auditory region of the caudal telencephalon using stereotaxic coordinates relative to the bifrucation of the midsagittal sinus (1.8-2.8 $\mathrm{mm}$ anterior, $1.4-1.6 \mathrm{~mm}$ lateral). Recordings were made at a range of depths relative to the brain surface $(0.806-3.237 \mathrm{~mm})$. Body temperature was maintained at $40^{\circ} \mathrm{C}-42^{\circ} \mathrm{C}$ throughout the recording sessions (TC-1000 Temperature Controller, CWE). Up to three recording tracks were made in each bird.

Spikes were amplified 10,000× (ISO-80, World Precision Instruments; and MA3, Tucker Davis Technologies), filtered $0.1-10 \mathrm{kHz}$ (Krohn-Hite model 3550), digitized at 24.4 samples/s (RX6 multifunction processor, Tucker Davis Technologies), and monitored online. Custom MATLAB scripts (David Schneider and Sarah Woolley, Columbia University) were used to analyze raw waveforms offline to ensure that only well-isolated single units were included in the dataset (Caras et al., 2012). Isolation was assessed using the following criteria: (1) a stable waveform shape, (2) a high $(>4)$ signal-to-noise-ratio, and (3) the absence of any interspike intervals $<1 \mathrm{~ms}$. The vast majority of analyzed recordings (230/246) met the criteria for single units. The remaining 16 recordings demonstrated two separable waveforms with high signal-tonoise ratios. These waveforms were manually sorted offline, and isolation was verified by principal components analysis.

Songbird auditory processing may be lateralized, but lateralization depends on a number of factors, including species, anesthesia, brain region, analysis type, sex, and stimuli (Cynx et al., 1992; George et al., 2004, 2005; Avey et al., 2005; Hauber et al., 2007; Poirier et al., 2009; Phan and Vicario, 2010). Therefore, to avoid a potential lateralization confound, we chose to focus only on the right hemisphere for these experiments.

Stimulus delivery and calibration. The stimulus delivery system and calibration procedures have been used previously (Caras et al., 2010, 2012). A custom-made sound delivery tube enclosing a small speaker (Etymotics ER-2B) and microphone (Etymotics ER-10B) was positioned flush against the skull around the left external auditory meatus and sealed with Petroleum jelly. Custom scripts (Python) delivered stimuli through an RX6 multifunction processor (Tucker Davis Technologies).

For our initial experiments, we used a band-limited white-noisegenerated calibration table of sound pressure levels (dB SPL re: $20 \mu \mathrm{Pa}$ ) to determine root-mean squared sound pressure levels (RMS dB SPL) for song stimuli. In later experiments, we determined RMS dB SPL values separately for each song. The levels for earlier recordings were corrected for each song type presented. RMS intensities for song stimuli were reliable within $\leq 4.9 \mathrm{~dB}$ SPL.

Auditory stimuli. The auditory stimuli used in this study have been described elsewhere (Caras et al., 2012). Songs were recorded (Syrinx, John Burt, www.syrinxpc.com) from 7 individual breeding-condition male Gambel's white-crowned sparrows. Each bird contributed one song to the stimulus set. One of these males was also used as subject in this study but was never presented with playback of his own song.

Data acquisition. Data acquisition procedures have been described previously (Caras et al., 2012). Briefly, bursts of band-limited white noise $(0.25-8 \mathrm{kHz})$ at $80 \mathrm{~dB}$ SPL were used as a search stimulus. Once a cell was isolated, one song, chosen at random, was presented at a rate of $0.14 / \mathrm{s}$.

Because we wished to examine neural coding of intensity discrimination, we presented stimuli at a wide range of amplitudes $(-10$ to 110 RMS dB SPL). Within that range, however, each cell was only presented with 9 different (but consecutive) intensities. Songs were presented in $10 \mathrm{~dB}$ descending steps, with 10 trials at each intensity. It is important to note that many avian species are capable of generating high-amplitude vocalizations; maximum values from 74 to $111.5 \mathrm{~dB}$ SPL have been reported at a distance of $1 \mathrm{~m}$ (Brackenbury, 1979; Brenowitz, 1982; Nemeth, 2004). Therefore, we consider the stimulus intensities used in these experiments to be within a behaviorally relevant range.

Computational methods. Our goal was to analyze the ability of individual neurons to reliably discriminate among song intensities, and to determine whether sex-steroid hormones affect this process. In order for a single neuron to successfully discriminate intensity, the spike trains elicited by repeated song presentations at the same sound level should be more similar to one another than the spike trains elicited by song presentations at different sound levels. To compute the similarity between pairs of spike trains elicited by a single cell, we adopted a spike train classifier (Machens et al., 2003; Narayan et al., 2006; Wang et al., 2007; Billimoria et al., 2008). As illustrated in Figure 1A, 9 dB SPL levels of a conspecific song were presented to each cell and each level was repeated 10 times, yielding nine raster plots of 10 repetitions at each level. One spike train from each raster was randomly chosen as a template for that $\mathrm{dB}$ SPL value. The remaining spike trains were then classified as belonging to a particular level based on the dB SPL of the template it matched most closely (Fig. $1 B, C$ ). If a spike train was equally well matched with two or more templates, it was randomly assigned to one of the matches. If a spike train was assigned to the $\mathrm{dB}$ SPL that evoked it, the 
A

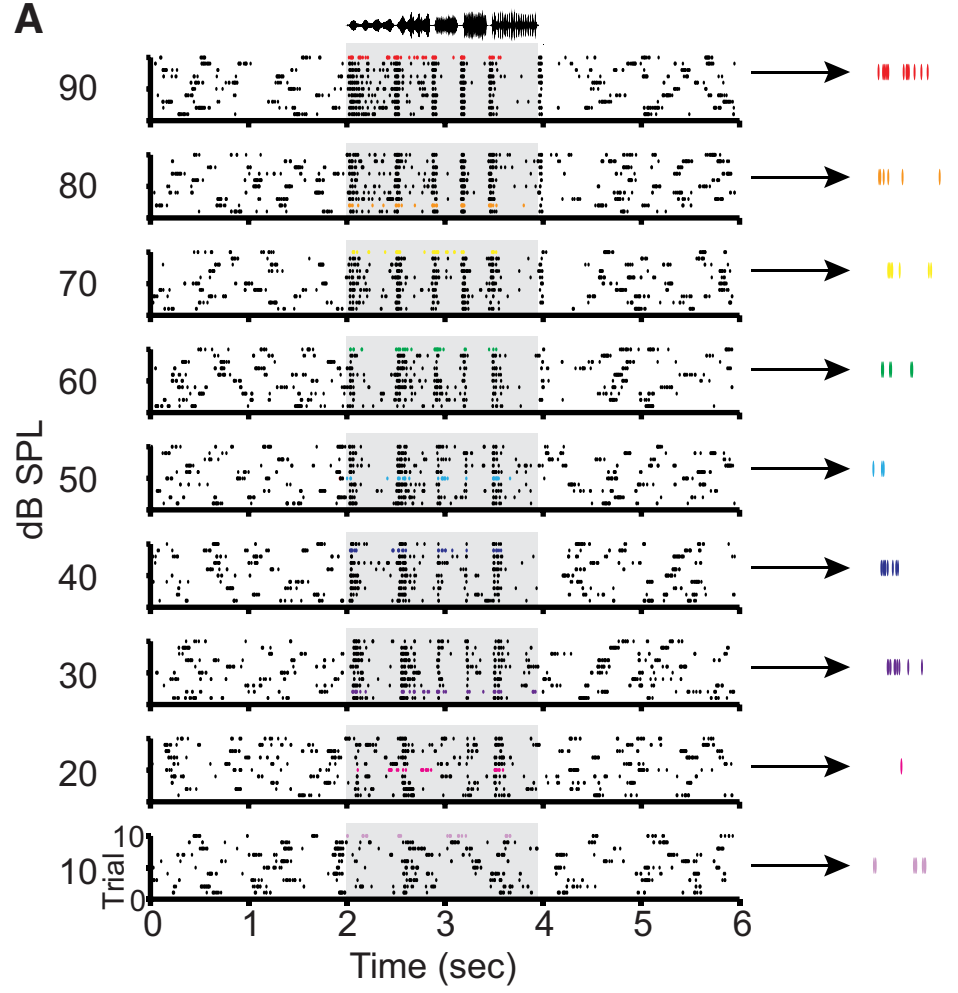

Templates

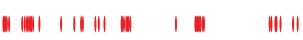

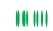

|| ||

| II

IIII IIII | । IIII

| | || || || || || | | ||

|| || || || ||

II

B \# Spikes

Templates

$\mathrm{dB} S P L$

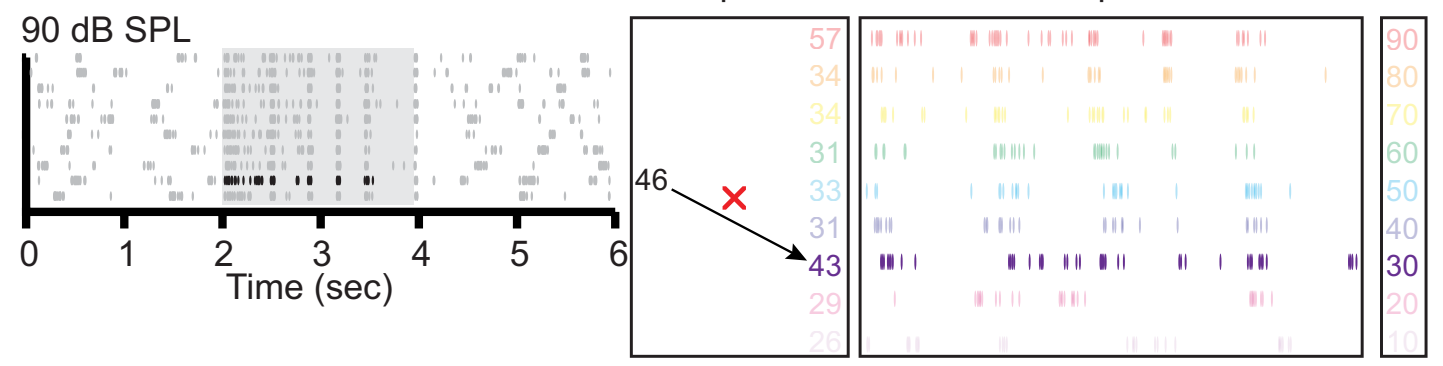

C

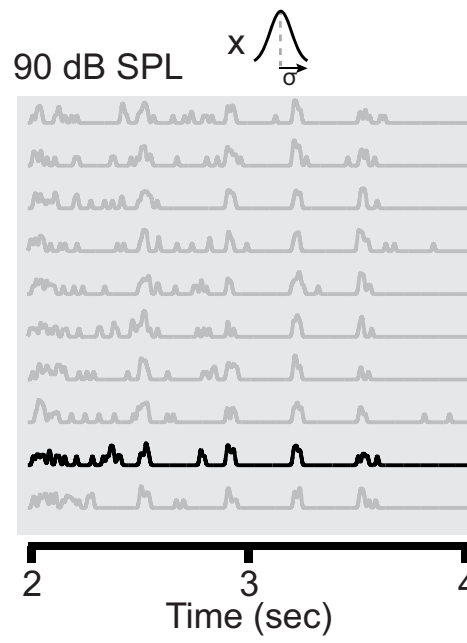

Rcorr

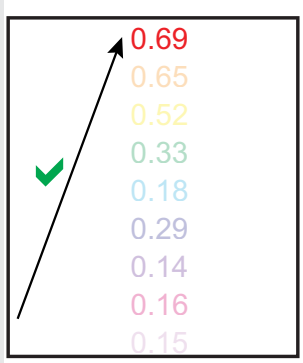

Templates

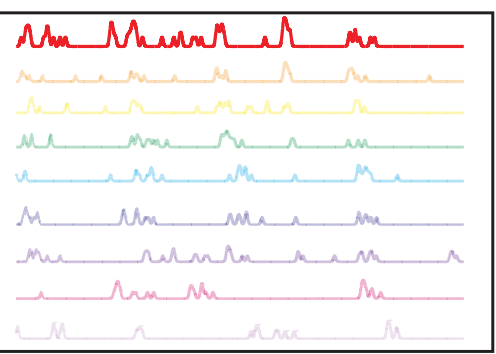

dB SPL

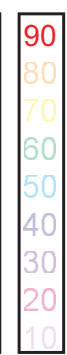

\section{Time (sec)}

Figure 1. Two methods of measuring the consistency with which individual neurons respond to different signal intensities. The "spike count" method is based on the number of spikes elicited during repeated presentations of a stimulus at a given intensity. The "spike timing" method is based on the temporal reliability of spikes during repeated presentations of the stimulus at a given intensity (for full details, see Materials and Methods).A, Left, Representative raster plots from a single neuron recorded from a breeding female. Each plot was generated in response to 10 presentations of a conspecific song whose amplitude envelope is shown at the top of the figure. Gray shaded regions represent song duration. Plots are arranged by song intensity (indicated by dB SPL values on the left). Template spike trains are colored and are enlarged on theright. $\boldsymbol{B}$, Demonstration of a spike count-based level assignmentfor asingle nontemplatespiketrain (blacktrain at left) generated by a $90 \mathrm{dBSPL}$ stimulus (data areenlarged from A). $\boldsymbol{C}$, Demonstration of a spike timing-based level assignment for the same nontemplate spike train illustrated in $\boldsymbol{B}$. In this example, spike trains were convolved with a Gaussian window, with $\sigma$ set to the optimal value for this neuron ( $4 \mathrm{~ms}$ ). 
assignment was considered "correct." The percentage of correctly assigned spike trains was calculated after all assignments had been made.

The methods outlined above describe the classification of spike trains after a single, random selection of templates. Ideally, one would repeat this process for all possible template combinations, and then calculate the percentage of correct assignments, averaged across all permutations. Spike trains were recorded for 10 presentations of song at nine different sound levels, leading to a total of $10^{9}$ possible template combinations; repeating the classification process for all template combinations was therefore deemed computationally unfeasible. Instead, we limited the number of classifier repetitions to 1000 for each cell. Discrimination accuracy was quantified as the percentage of correctly assigned spike trains, averaged over the 1000 estimates generated by the classifier. Discrimination accuracy was also computed on an intensity-by-intensity basis.

If a cell is capable of discriminating among different intensities, we would expect that its individual spike trains would be classified correctly more often than would be expected by chance. Each cell was presented with nine different stimulus levels; thus, chance performance of the classifier is $1 / 9(11 \%)$. All aspects of the data analysis were performed using custom scripts written in MATLAB by one of the authors (M.L.C.).

Our classifier describes the ability of a neuron to discriminate among dB SPL values of a particular song. To assess intensity coding in a broader sense (i.e., the ability of a neuron to discriminate sound level, regardless of the spectrotemporal details of the stimulus), one would need to present each cell with several different conspecific songs at different sound levels. In our hands, neurons can be held in isolation for up to 15-30 min on average, making it impractical to explore both song identity and song level. Thus, as stated above, each cell was presented with a single song, at a range of sound intensities. Therefore, for the remainder of this paper, when we speak of "intensity coding" or "intensity discrimination," we note that there is an implicit assumption that the song identity is already known.

Classification metrics. Because we were interested in comparing the relative roles of count-based and timing-based encoding strategies, we chose to quantify spike train similarity using two different metrics. For the "spike count" metric, spike trains were assigned to the template with the closest number of action potentials, neglecting all temporal information. An example of the classification of a single spike train using the spike count metric is illustrated in Figure $1 B$.

For the "spike timing" metric, we used an established correlationbased measure of spike timing reliability, Rcorr (Schreiber et al., 2003; Wang et al., 2007). All spike trains (including templates) were smoothed with a Gaussian filter of mean 0 and $\mathrm{SD} \sigma$. The temporal similarity of a smoothed spike train, $\vec{s}_{i}$, and a smoothed template train, $\vec{s}_{j}$, was calculated as follows:

$$
R \operatorname{corr}=\frac{\vec{s}_{i} \cdot \vec{s}_{j}}{\left|\vec{s}_{i}\right|\left|\vec{s}_{j}\right|}
$$

Rcorr is a normalized measure ranging from 0 to 1 . A value of 1 indicates a perfect correlation between the spike train and the template; 0 indicates no relationship. Spike trains were assigned to the template that produced the maximum value of Rcorr.

This metric reflects a "timing-based" coding scheme, whose temporal resolution is determined by $\sigma$. An optimal $\sigma$ is small enough to capture the dynamics of spiking activity on a fine time scale, but large enough to allow for negligible amounts of jitter in the spike times. We did not know a priori what the optimal $\sigma$ was, and it was possible that it differed for each cell. Therefore, we classified spike trains after smoothing with filters of the following widths: $1,2,4,8,16,32,64,128$, and $256 \mathrm{~ms}$. The $\sigma$ that generated the highest percentage of correct classifications was considered the optimal $\sigma$; all of the spike timing data reported here were generated at each cell's optimal $\sigma$. An example of the assignment of a single spike train using the timing metric is illustrated in Figure $1 C$.

Assessment of significance. To assess the statistical significance of our percentage correct estimates, we adopted a trial-shuffling approach: individual spike trains of each neuron were randomly assigned to dB SPL values, thus removing intensity-specific information, as illustrated in
Figure 2. Shuffled spike trains were then classified, and the classification procedure was repeated 1000 times, as described above. This process generates a distribution of random percentage correct values that would be expected in the absence of intensity-specific encoding. The distribution for the original, unshuffled dataset was compared with the shuffled (random) distribution: discrimination was considered statistically significant if the average of the original distribution exceeded the value of the 95th percentile of the shuffled distribution (Fig. 2). Similar approaches have been used previously (Wang et al., 2007; Mesgarani et al., 2008; Huetz et al., 2009).

Histology. Histological and electrode track reconstruction procedures have been described previously (Caras et al., 2012). Briefly, electrode tracks were marked by two injections using either iontophoresis $(10 \%$ fluororuby, 39/40 birds, BAB-501 Iontophoresis pump, Kation Scientific) or pressure injection (10\% BDA, 1/40 birds, Parker Picospritzer). At the end of each recording session, birds were perfused (PBS, followed by $4 \%$ PFA). Brains were dissected from the skull, postfixed, cryoprotected, and embedded in gelatin. Parasagittal $40 \mu \mathrm{m}$ sections were cut on a freezing microtome and mounted onto gelatin-subbed slides. Alternate sections were processed for Nissl or air dried until fluorescent or BDA processing.

Sections containing fluororuby were cleared, coverslipped, and dried overnight. Sections containing BDA were incubated in 30\% hydrogen peroxide in $100 \%$ methanol, rehydrated in PBS, and visualized using the ABC-DAB method (Vector Laboratories, Sigma). All images were captured on a Olympus $\mathrm{BH} 2$ microscope fitted with a Qimaging camera and Qcapture software.

Of the 246 cells in our analysis, 222 of them were localized to either the caudal mesopallium (CM) or Field L. Twenty-four cells were on the border between $\mathrm{CM}$ and $\mathrm{L}$ and could not be definitively localized to one region or another (see Table 2). We note that Field $\mathrm{L}$ is a heterogeneous complex made up of different subregions that demonstrate differences in spectrotemporal tuning (Sen et al., 2001; Nagel and Doupe, 2008; Kim and Doupe, 2011). It is therefore possible that intensity discrimination and/or the effect of breeding condition differ among these subnuclei, or between $\mathrm{CM}$ and Field $\mathrm{L}$ as whole. Previous investigations of song discrimination using similar computational methods to those described here have treated Field L as a single entity (Narayan et al., 2006; Wang et al., 2007; Billimoria et al., 2008), and others have pooled cells from CM and Field L together for large-scale analyses of physiological response properties (Grace et al., 2003). Because of the multidimensional nature of our experimental design and the distinct findings we observed for specific response patterns (see Results), we lacked sufficient statistical power to separate cells into further subcategories and have therefore chosen to pool our cells for analysis. The distribution cell types for each anatomical region can be found in Table 3 , however, and are discussed in more detail in Results.

Hormone measurement. We collected blood from the alar wing vein of each bird into a heparinized tube and centrifuged the sample at $4^{\circ} \mathrm{C}$ immediately before each recording session. We stored separated plasma at $-80^{\circ} \mathrm{C}$ until ELISA was performed. Plasma levels of $17-\beta$ estradiol were assayed using a kit from Cayman Chemicals. All of the estradiol levels reported here were originally measured for a previous study (Caras et al., 2012). Plasma testosterone levels were assayed using a standard kit from Enzo Life Sciences (formerly Assay Designs) that has been successfully used with white-crowned sparrow plasma (Caras et al., 2010).

Briefly, aliquots of each sample were run with kit standards following each kit's protocol. Each steroid was measured in a single assay. Some female samples were lost during preparation; therefore, only 7 of 9 breeding female samples and 7 of 12 nonbreeding female samples were assayed. Most samples and all of the kit standards were run in duplicate; however, 3 breeding female and 2 nonbreeding female samples were run singly because of insufficient sample volume. Because testosterone levels in breeding males can exceed the highest range of the kit's detectability (2 $\mathrm{ng} / \mathrm{ml}$ ), we made a 1:20 dilution of each breeding male sample with assay buffer. After incubating samples with antiserum and a steroid-enzyme conjugate, wells were emptied and washed, and substrate was added to all sample wells. Plates were read immediately at $405 \mathrm{~nm}$ on a Dynex MRX II microplate reader. 


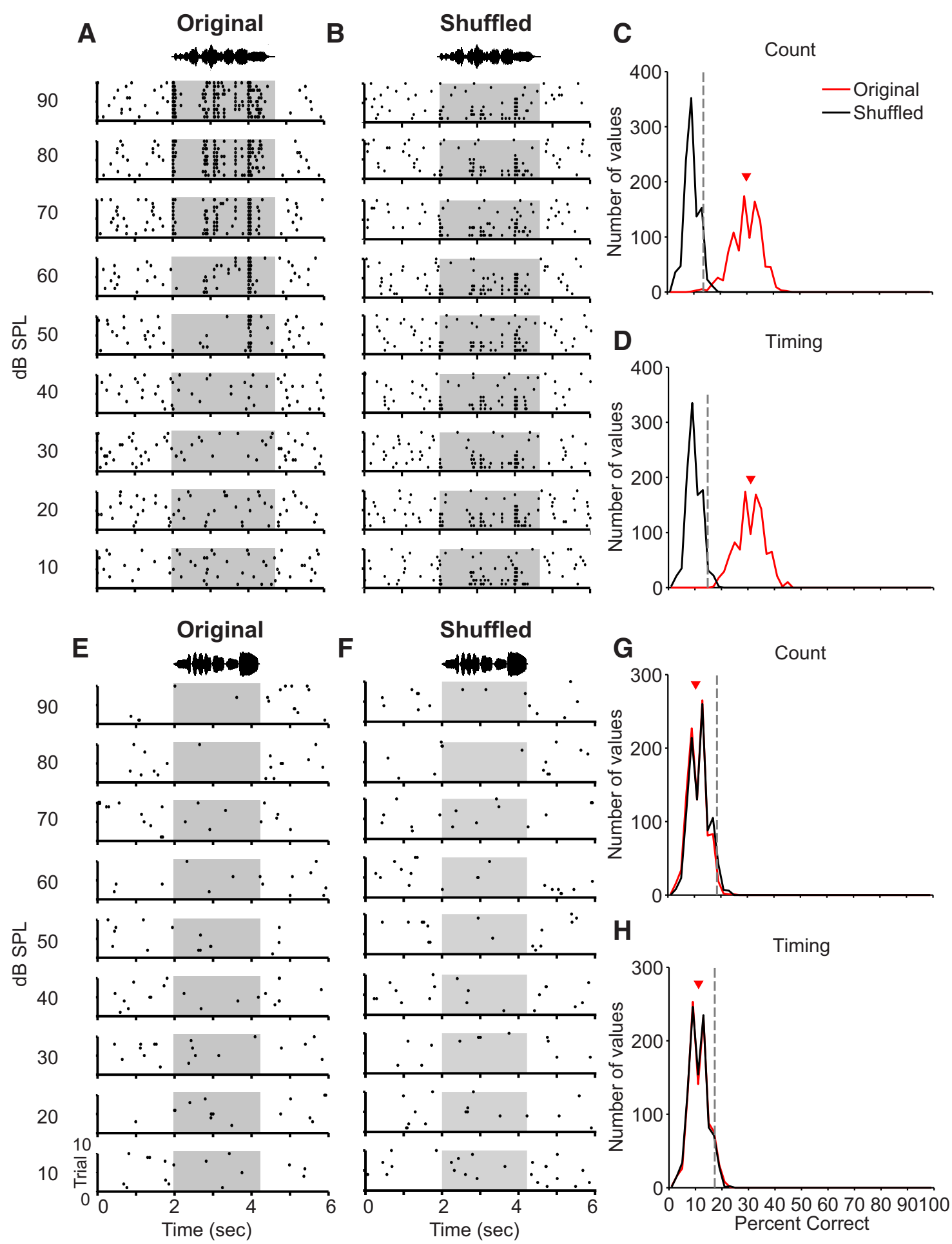

Figure 2. Demonstration of trial shuffling approach. Trial shuffling removes intensity-specific information, generating a distribution of random percentage correct values. To assess statistical significance, the distribution of the original (unshuffled) dataset is compared with 95th percentile of the shuffled (random) distribution (for full details, see Materials and Methods). $\boldsymbol{A}$, Representative raster plots from a single "bicoding" neuron recorded from a nonbreeding male (see Results and Fig. 3). Same plot conventions as in Figure 1A. $\boldsymbol{B}$, Raster plots for the same unit as in $\boldsymbol{A}$, after shuffling trials to remove intensity-specific information. C, Distributions of count-based percentage correct values for the original (red) and trial-shuffled (black) data. Each distribution incorporates 1000 percent correct estimates ( 1 for each repetition of the pattern classifier). Red triangle represents mean for the original distribution; gray dashed line indicates the 95th percentile of the shuffled distribution. $\boldsymbol{D}$, Distributions of timing-based percentage correct values. Plot conventions are identical to $\boldsymbol{C}$. $\boldsymbol{E}-\boldsymbol{H}$, Raster plots $(\boldsymbol{E}, \boldsymbol{F})$ and percentage correct distributions $(\boldsymbol{G}, \boldsymbol{H})$ for a single unit recorded from a nonbreeding female classified as incapable of intensity discrimination.

We plotted the optical densities of the kit standards as a function of known hormone concentration and fit the points with a sigmoid 4PLC equation; sample hormone levels were extrapolated from this standard curve. Intra-assay variability was $6.50 \%$ for estradiol and $9.94 \%$ for testosterone.
Statistics. Comparisons consisting of only two groups were performed with two-sample Student's $t$ tests. If the groups violated the assumptions of normality, a nonparametric equivalent (Wilcoxon rank sum test) was used instead. To assess the effect of breeding condition on discrimination accuracy, we performed two-way (intensity $\times$ condition) mixed model 
Table 1. Plasma hormone levels ${ }^{a}$

\begin{tabular}{lllll}
\hline & Nonbreeding & Breeding & Statistic & $p$ \\
\hline $\begin{array}{l}\text { Testosterone } \\
(\mathrm{ng} / \mathrm{ml})\end{array}$ & $0.376 \pm 0.08(n=10)$ & $21.92 \pm 3.73(n=9)$ & $-5.77^{*}$ & $<0.0001$ \\
$\begin{array}{l}\text { Estradiol } \\
(\mathrm{pg} / \mathrm{ml})\end{array}$ & $18.77 \pm 3.51(n=6)$ & $447.45 \pm 214.00(n=6)$ & $-2.80^{* *}$ & $<0.01$ \\
\hline adata are mean \pm SEM. & & & \\
*Student's $t$ test. \\
**Wilcoxon Z test.
\end{tabular}

Table 2. Breakdown of cells included in analysis ${ }^{a}$

\begin{tabular}{lcccl}
\hline & CM & CM/L border & Field L & Total \\
\hline Breeding females & $12(6)$ & $5(4)$ & $40(9)$ & $57(9)$ \\
Nonbreeding females & $11(6)$ & $5(3)$ & $56(12)$ & $72(12)$ \\
Breeding males & $19(8)$ & $7(5)$ & $33(9)$ & $59(9)$ \\
Nonbreeding males & $7(5)$ & $7(6)$ & $44(8)$ & $58(10)$ \\
Total & $49(25)$ & $24(18)$ & $173(38)$ & - \\
\hline
\end{tabular}

${ }^{a}$ Values are number of cells (number of birds). The number of birds indicated in the right-most column is not a simple sum of the number of birds in each preceding column because units from each anatomical location may have been recorded in the same bird.

ANOVAs; separate analyses were performed for males and females. Not all cells were tested with identical intensity ranges. Missing values present an obstacle for running a repeated-measures ANOVA; we therefore restricted our group analyses to $20-80 \mathrm{~dB}$ SPL, allowing inclusion of the vast majority of our neurons. Unless otherwise stated, all values are reported as mean \pm SEM. All statistical analyses were made using JMP 9.0.1 (SAS). The female data presented here were originally collected for previous study that examined estrogenic effects on average sound-evoked firing rates (Caras et al., 2012).

\section{Results}

\section{Plasma hormone levels}

Females housed under breeding condition had higher levels of plasma estradiol than their nonbreeding housed counterparts (Table 1). These levels are similar to the physiological range reported for wild breeding female white-crowned sparrows ( $\sim 300-500 \mathrm{pg} / \mathrm{ml}$ ) (Wingfield and Farner, 1978). Breeding condition also elevated testosterone levels in our male birds (Table $1)$, although the breeding levels we report here are higher than what has been observed in wild breeding males $(4-10 \mathrm{ng} / \mathrm{ml})$ (Wingfield and Farner, 1978).

Although sex steroids play an important role in mediating seasonal breeding plasticity (Brenowitz, 2008; for review, see Bass, 2008; Sisneros, 2009), it should be noted that potential steroid-independent effects of photoperiod may partly contribute to the results presented here (Smith et al., 1997; Soma et al., 1999; Riters et al., 2001; Park et al., 2005). We therefore present the results below in the context of "breeding condition," which represents the combination of photoperiod and hormone manipulations in this study.

\section{Single units form three classes on the basis of intensity coding capabilities}

We analyzed the intensity discrimination of 246 single units using spike count-based and spike timing-based pattern classifiers ( $\mathrm{Ta}-$ ble 2). Of the 246 cells localized to CM or Field L, 91 were incapable of significantly discriminating song intensities using either spike count or spike timing information; subsequent examination of corresponding raster plots suggested that these cells did not respond to song stimuli, and we therefore removed them from the analysis (Fig. 2).

The remaining 155 cells were capable of discriminating song intensities on the basis of only spike timing information, only spike count information, or both spike timing and spike count information. For simplicity, we will refer to these neurons for the remainder of this paper as "temporal" cells, "count" cells, and "bicoding" cells, respectively.

Representative raster plots for each response category (Fig. 3) suggest distinct differences in response magnitude and temporal structure as a function of song intensity. These differences were verified quantitatively by calculating average firing-rate inputoutput functions for each group. As shown in Figure $4 A$, at low sound levels, each cell group had an average firing rate of $\sim 3 \mathrm{~Hz}$, likely reflecting spontaneous activity. As song intensity increases, count cells demonstrate suppressed activity. Conversely, temporal cells display steady firing rates, regardless of stimulus intensity. Bicoding cells, on the other hand, increase their firing rates in a monotonic manner as song intensity increases.

These three categories of cells cluster into distinct groups when plotted as a function of spike count-based and spike timing-based discrimination accuracy (Fig. 4B). On average, bicoding neurons (red diamonds) outperformed temporal cells (blue squares) on spike timing-based intensity discrimination by $\sim 8 \%(26.87 \pm 1.24$ vs $18.56 \pm 0.56, Z=5.79, p<0.0001)$. Similarly, bicoding neurons showed superior spike count-based performance compared with count cells (red diamonds vs gray squares; $25.15 \pm 1.11$ vs $17.65 \pm 0.58, Z=-3.75, p<0.001$ ). Together, these findings indicate that the avian auditory forebrain is capable of using both spike count and temporal information to encode song intensity, and song-responsive cells within this region form 3 distinct classes on the basis of their individual encoding capabilities.

To determine whether these functionally distinct cell types segregate anatomically, we compared their relative proportions within CM, Field L, and the CM/L border. As shown in Table 3, there were significant differences: although bicoding and temporal cells were observed at approximately equal rates in Field L, the distribution was biased toward temporal cells in $\mathrm{CM}\left(\chi_{2}^{4}, N=\right.$ $155=9.44, p=0.05)$.

In addition, we examined whether the distribution of cell types varied as a function of sex and/or breeding condition. Overall, the relative proportions of each cell type were similar in males and females $\left(\chi_{2}^{2}, N=155=2.85, p=0.24\right)$, and across breeding states $\left(\chi_{2}^{2}, N=155=5.14, p=0.08\right)$. A separate analysis, however, revealed that breeding condition has a robust sex-specific effect: in females, the cellular distribution switches from primarily bicoding cells under nonbreeding condition, to primarily temporal cells under breeding condition $\left(\chi_{2}^{2}, N=80=8.86, p=\right.$ 0.01 ; Table 4$)$. No effect of breeding condition was observed in males $\left(\chi_{2}^{2}, N=75=0.12, p=0.94\right)$. Given that CM has a higher proportion of temporal cells (Table 3 ), it was possible that the difference observed in females reflected unequal sampling of anatomical sites across breeding conditions, rather than an effect of breeding condition per se. In fact, all anatomical regions were sampled at approximately equal rates in breeding and nonbreeding females $\left(\chi_{2}^{2}, N=80=0.70, p=\right.$ 0.70 ; also see Table 2$)$, suggesting that the coding strategies of individual female cells may be malleable, and depend on reproductive context.

\section{Male intensity discrimination is unaffected by breeding condition}

Previous work revealed that sex steroids can affect auditory forebrain neurons in a cell-selective manner (Caras et al., 2012), leading us to hypothesize that hormonal modulation of intensity discrimination may occur in a particular cell type. To 

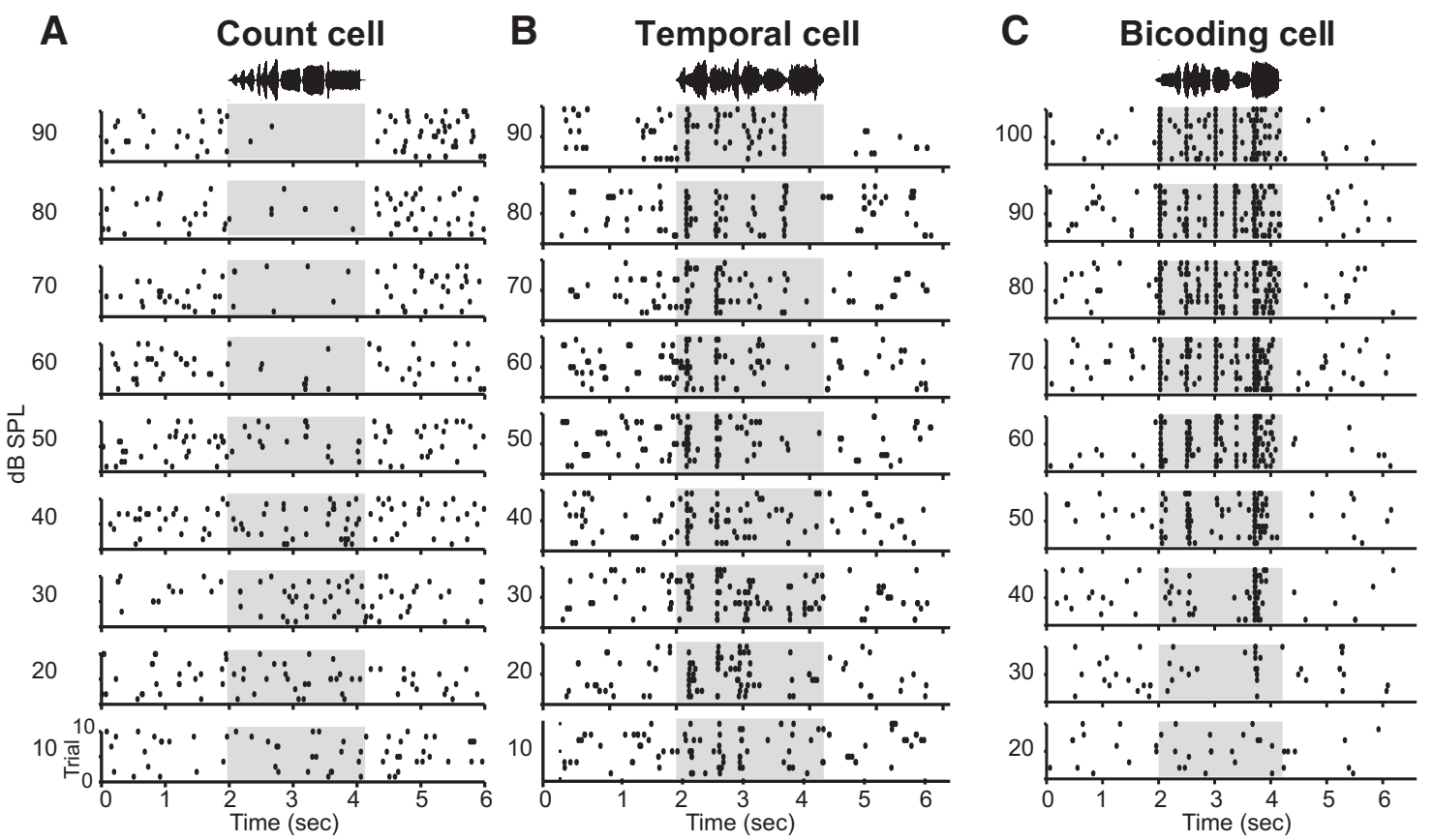

Figure 3. Cells from three functionally distinct types. $\boldsymbol{A}-\boldsymbol{C}$, Representative raster plots from a cell in each of the response categories noted in the text and below. Plot conventions as in Figure 1. $\boldsymbol{A}$, Representative raster plots from a count cell recorded in a nonbreeding female illustrate neural suppression at high song amplitudes. $\boldsymbol{B}$, Representative raster plots from a temporal cell recorded in a breeding male show relatively little change in overall activity across song intensities but clear spike timing-based responses. $C$, Representative raster plots from a bicoding cell recorded in a nonbreeding male demonstrate both increased activity and precise spiking as song intensity increases.
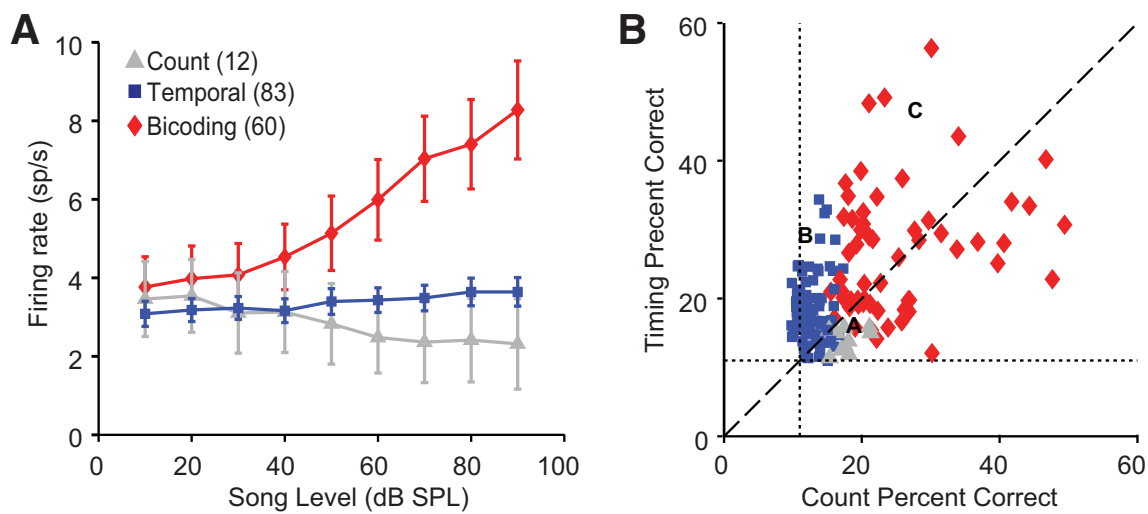

Figure 4. A, Data are mean \pm SEM song-evoked firing rate-level profiles for each cell group. Firing rates for each cell were averaged across the entire song duration. Count cells (gray triangles) display monotonically decreasing firing rates as song level increases. Temporal cells (blue squares) display flat rate-level functions. Bicoding cells (red diamonds) show monotonically increasing firing rates as song amplitude increases. B, Scatter plot illustrating the spike timing-based ( $y$-axis) and spike count-based ( $x$-axis) percentage correct values for each cell in the dataset. Symbols and colors (same as $A$ ) indicate cell type. Letters indicate the representative cells shown in Figure 3. Dotted lines indicate chance performance.

Table 3. Anatomical distributions of cell types ${ }^{a}$

\begin{tabular}{llllc}
\hline & Bicoding & Count & Temporal & Total (cells) \\
\hline CM & $21.9 \%(7)$ & $12.5 \%(4)$ & $65.6 \%(21)$ & 32 \\
CM/L & $23.1 \%(3)$ & $0.0 \%(0)$ & $76.9 \%(10)$ & 13 \\
L & $45.4 \%(50)$ & $7.3 \%(8)$ & $47.3 \%(52)$ & 110 \\
Total (cells) & 60 & 12 & 83 & 155 \\
\hline
\end{tabular}

avalues are percentages of cells within each anatomical region. Actual numbers of recording sites are in parentheses. Table 4. Effect of sex and condition on cell type distributions ${ }^{a}$

\begin{tabular}{llllc}
\hline & Bicoding & \multicolumn{1}{l}{ Count } & Temporal & Total (cells) \\
\hline Breeding females & $30.3 \%(10)$ & $0.0 \%(0)$ & $69.7 \%(23)$ & 33 \\
Nonbreeding females & $53.2 \%(25)$ & $8.5 \%(4)$ & $38.3 \%(18)$ & 47 \\
Breeding males & $31.6 \%(12)$ & $10.5 \%(4)$ & $57.9 \%(22)$ & 38 \\
Nonbreeding males & $35.1 \%(13)$ & $10.8 \%(4)$ & $54.1 \%(20)$ & 37 \\
Total (cells) & 60 & 12 & 83 & 155
\end{tabular}

${ }^{a}$ Values are percentages of cells. Actual numbers of recording sites are in parentheses. explore this possibility, we examined the effect of breeding condition on the neural discrimination of song intensity after grouping cells according to their encoding capabilities (Figs. 3 and 4). Males and females were analyzed separately. We report our findings for male birds first.

To visualize the impact of breeding condition on discrimination accuracy, we created confusion matrices whose rows indicate the actual stimulus intensity and whose columns indicate the intensity assignment made by the classifier. Correct estimates fall along the diagonal from the upper left to the bottom right of each matrix. The percentage of spike train assignments for each stimulus level is represented by color, with warmer colors indicating higher percentages. Figure $5 A, B$ shows spike count-based matrices for count cells from breeding and nonbreeding males. A two-way mixed model ANOVA revealed a moderate effect of intensity $\left(F_{(6,36)}=3.22, p=0.01\right)$, arising from the slightly higher discrimination accuracy at very low and very high $\mathrm{dB}$ SPL values (the upper left and bottom right corners of the matrices, respectively). A comparison of the original matrices (Fig. $5 A, B$ ) suggests no effect of breeding condition $\left(F_{(1,6)}=0.26, p=0.63\right)$, nor a level $\times$ condition interaction $\left(F_{(6,36)}=1.33, p=0.27\right)$. A similar conclusion is drawn by examining Figure $5 C$, which illustrates a subtracted difference matrix (i.e., the nonbreeding matrix subtracted from the breeding condition matrix). Caution is warranted when interpreting these results, however, as relatively few count cells were observed overall ( $n=4$ for each group). 

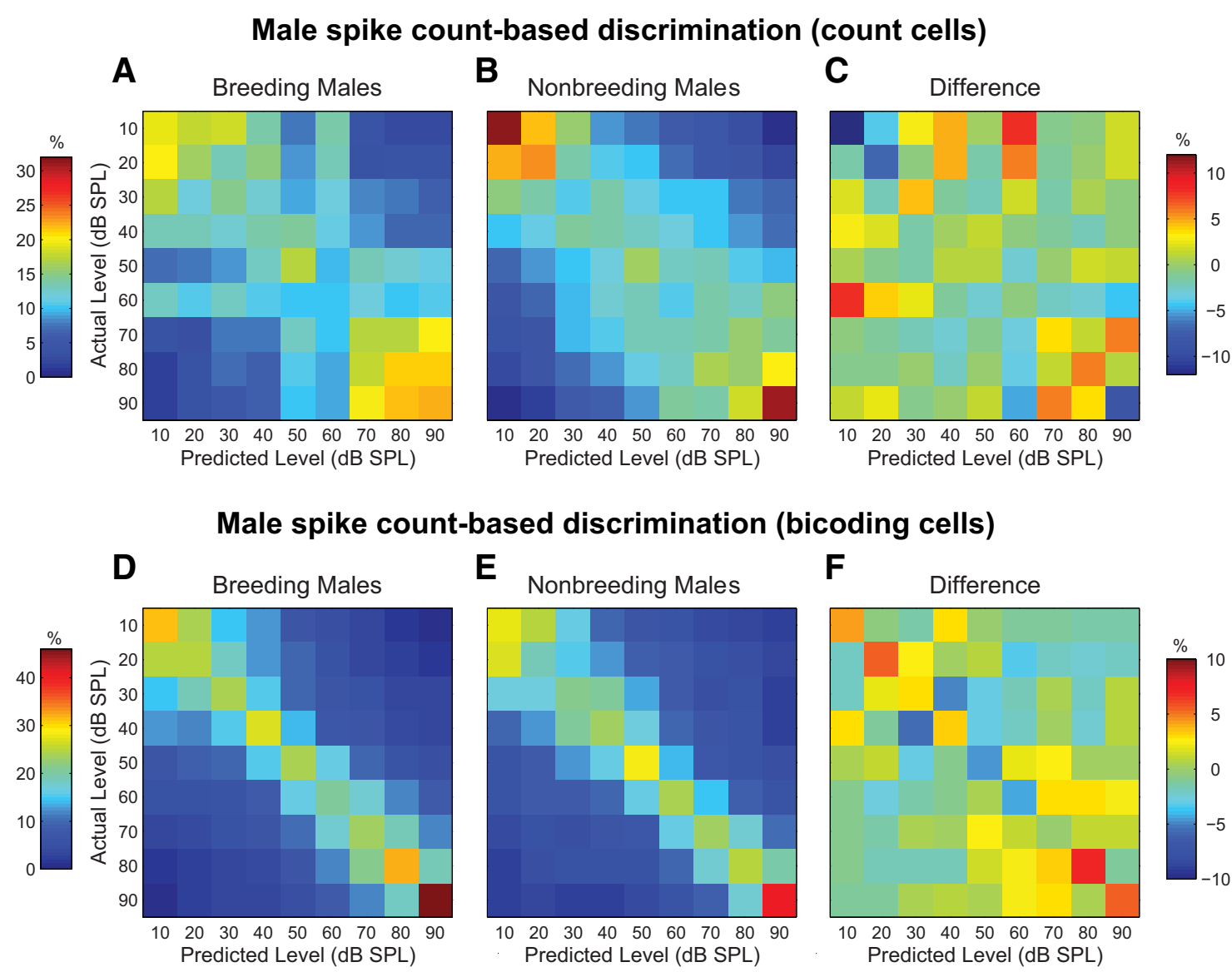

Figure 5. Breeding condition does not affect male spike count-based intensity discrimination. $A$, Spike count-based confusion matrix for count cells from breeding males. Rows represent actual song intensity levels; columns represent song intensity levels predicted by the spike count-based classifier. Correct estimates fall along the diagonal running from the upper left to the bottom right corner. The percentage of spike train assignments are represented by color, as indicated by the bar on the left. Plot conventions are identical for $\boldsymbol{B}, \boldsymbol{D}$, and $\boldsymbol{E}$. B, Confusion matrix for count cells from nonbreeding males. C, Confusion matrix created by subtracting the nonbreeding male matrix in $\boldsymbol{B}$ from the breeding male matrix in $\boldsymbol{A}$. A different color scale is used, as indicated by the bar on the right. $\boldsymbol{D}$, Spike count-based confusion matrix for bicoding cells from breeding males. $\boldsymbol{E}$, Confusion matrix for bicoding cells from nonbreeding males. $\boldsymbol{F}$, Confusion matrix created by subtracting the nonbreeding male matrix in $\boldsymbol{E}$ from the breeding male matrix in $\boldsymbol{D}$.

A similar analysis was performed for male bicoding cells. As shown in Figure 5D, E, discrimination accuracy remains relatively constant across all song intensity levels $\left(F_{(3.44,65.38)}=1.52, p=0.21\right)$. Furthermore, the subtracted difference matrix (Fig. $5 F$ ) indicates no significant effect of breeding condition $\left(F_{(1,19)}=0.00, p=0.99\right)$, nor an interaction between breeding condition and song intensity $\left(F_{(3.44,65.38)}=0.80, p=0.51\right)$. Together, these results suggest that spike count-based intensity discrimination is not sensitive to male breeding state.

A separate analysis was performed to examine the impact of breeding condition on male spike timing-based discrimination. As shown in Figure 6, classifier performance improved as song intensity increased for both temporal cells (Fig. 6A, $B$; $\left.F_{(4.09,159.55)}=8.04, p<0.0001\right)$ and bicoding cells (Fig. $6 D, E$; $\left.F_{(2.61,49.68)}=9.43, p<0.0001\right)$. Subtracted difference matrices (Fig. 6C,F) revealed no effect of breeding condition for either cell group (temporal: $F_{(1,39)}=0.83, p=0.37$; bicoding: $F_{(1,19)}=$ $0.40, p=0.54)$, nor a level $\times$ condition interaction (temporal: $F_{(4.09,159.55)}=0.57, p=0.69$; bicoding: $F_{(2.61,49.68)}=0.52, p=$ $0.65)$. Collectively, these findings suggest that males are capable of both count-based and timing-based encoding of song intensity, and these capabilities are unaffected by changes in breeding condition.
Female spike timing-based intensity discrimination is sensitive to breeding condition in a cell-selective manner We next examined whether breeding condition affects female spike count-based intensity discrimination. No count cells were recorded in breeding females (Table 4), so no comparison could be performed for this cell type. However, for completeness, the confusion matrix generated by the 4 count cells recorded in nonbreeding females is shown in Figure $7 A$. No effect of level was observed $\left(F_{(6,12)}=0.89, p=0.53\right)$, likely due to the small sample size.

In female bicoding neurons, spike count-based discrimination accuracy was highest at the extreme intensity values, contributing to a significant effect of level $\left(F_{(3.21,93.28)}=4.91, p<0.01\right.$; Fig. $7 B, C)$. However, as shown in Figure $7 D$, there was no overall effect of breeding condition $\left(F_{(1,29)}=0.21, p=0.65\right)$, nor an interaction between breeding condition and song intensity $\left(F_{(3.21,93.28)}=1.37, p=0.26\right)$. Thus, like males, female spike count-based discrimination is unaffected by hormonal state.

Finally, we examined the effect of breeding condition on female spike timing-based intensity discrimination. As above, we created confusion matrices for temporal cells from breeding (Fig. $8 A$ ) and nonbreeding (Fig. $8 B$ ) females. Both matrices show an 

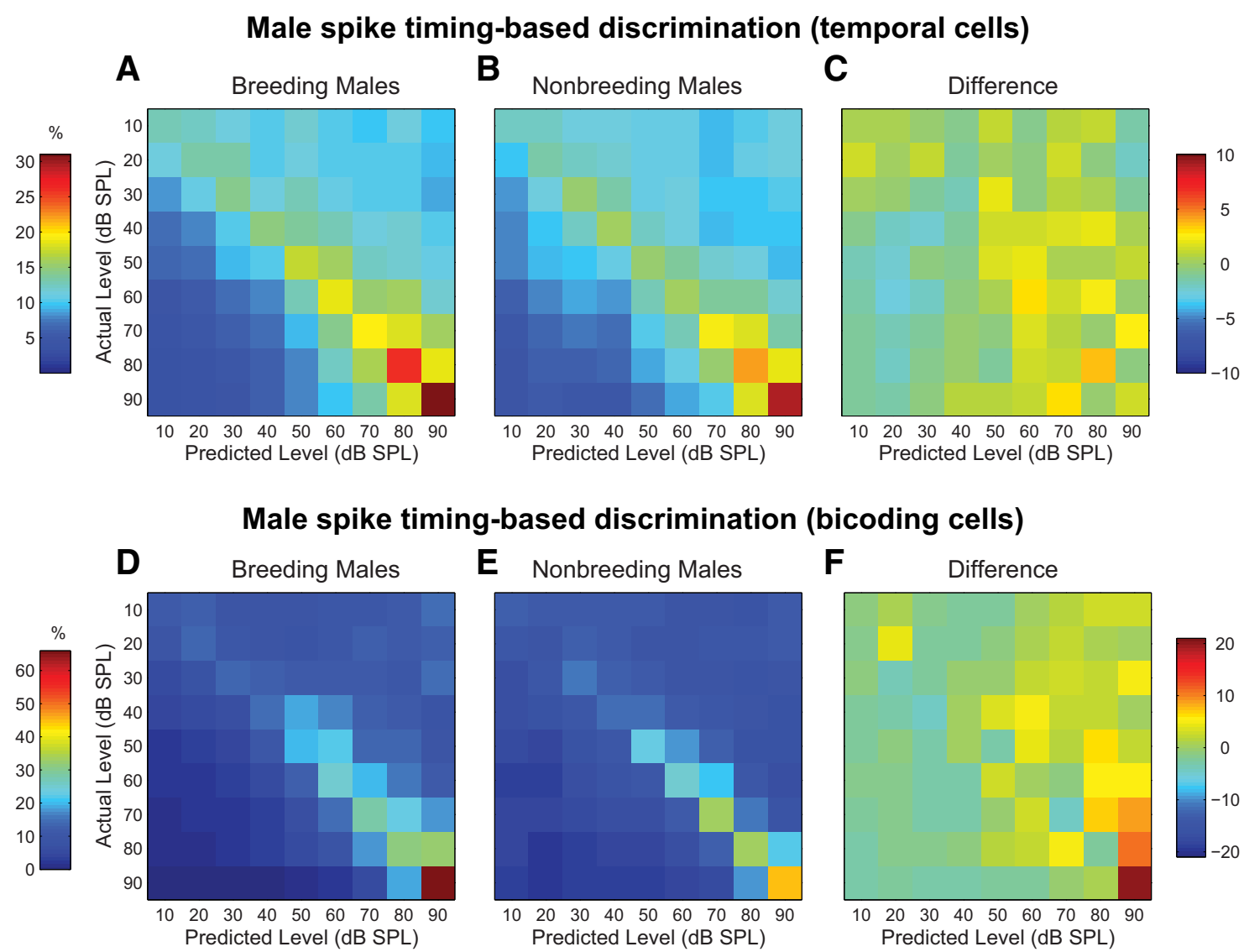

Figure 6. Breeding condition does not affect male spike timing-based intensity discrimination. $A$, Spike timing-based confusion matrix for temporal cells from breeding males. Plot conventions are identical to Figure 5. $\boldsymbol{B}$, Confusion matrix for temporal cells from nonbreeding males. $\boldsymbol{C}$, Confusion matrix created by subtracting the nonbreeding male matrix in $\boldsymbol{B}$ from the breeding male matrix in $\boldsymbol{A}$. Color scale is on the right. $\boldsymbol{D}$, Spike timing-based confusion matrix for bicoding cells from breeding males. $\boldsymbol{E}$, Confusion matrix for bicoding cells from nonbreeding males. $\boldsymbol{F}$, Confusion matrix created by subtracting the nonbreeding male matrix in $\boldsymbol{E}$ from the breeding male matrix in $\boldsymbol{D}$.

improvement in classifier performance as song level increases $\left(F_{(4.45,151.23)}=5.42, p<0.001\right)$. The subtracted difference matrix in Figure $8 C$, however, reveals no effect of breeding condition $\left(F_{(1,34)}=0.10, p=0.76\right)$, nor a level $\times$ condition interaction $\left(F_{(4.45,151.23)}=1.19, p=0.32\right)$.

For bicoding neurons, there was a similar effect of level, such that accuracy clearly improved with increasing song intensity $\left(F_{(3.06,88.76)}=7.86, p<0.0001\right.$; Fig. $\left.8 D, E\right)$. Here, however, there was also a robust effect of breeding condition: Bicoding neurons from breeding females (Fig. $8 D$ ) outperformed those from nonbreeding females (Fig. $8 E$ ) by an average of $11 \%\left(F_{(1,29)}=6.17\right.$, $p=0.02$ ). This effect is most easily observed by examining the difference between the breeding and nonbreeding female matrices, as shown in Figure $8 F$. Although the difference appears particularly strong for low and mid levels (20-50 dB SPL; orange and red squares in upper left quadrant), the level $X$ condition interaction was not significant $\left(F_{(3.06,88.76)}=0.80\right.$, $p=0.50)$. Together, these results suggest that, like males, females are capable of using count-based and temporal strategies to encode song intensity, but only spike-timing based encoding is sensitive to changes in hormonal state, and only in a cell-selective manner.

Breeding condition increases the range of discriminable intensities in females on a cell-by-cell basis

The previous analyses revealed an effect of breeding condition on female bicoding cells at a group level. In principal, this finding could be explained by one of two scenarios. First, breeding condition may increase the range of discriminable song intensities on a cell-by-cell basis. Alternatively, cells may be specialized for the discrimination of specific song intensities, and breeding condition may enhance performance for each cell (particularly those specialized for low-mid levels) without increasing their discriminable range.

To distinguish between these two possibilities, we examined the spike timing-based discrimination range for each female bicoding neuron. In Figure $9 A$, each cell is depicted along a single row. Within each row, thick solid lines connect consecutive intensities that the cell can discriminate at a statistically significant level. Solid points indicate isolated intensities that are significantly discriminable (see Materials and Methods); dashed lines are used as needed to fill in any gaps between the lowest and highest discriminable intensities for each cell; they serve as visual guides only and do not indicate successful discrimination. Cells are grouped according to breeding condition; within each group, cells are arranged in order of the minimum intensity discriminable. Qualitatively, it appears that bicoding cells from breeding females (top) have wider discrimination ranges than cells from nonbreeding females (bottom). This observation was verified by calculating the difference between the highest and the lowest significantly discriminable intensity (the "absolute range") for each cell that significantly discriminated at least 2 intensities. As shown in Figure 9B, bicoding cells from breeding females have absolute ranges that are, on average, $28 \mathrm{~dB}$ wider than bicoding 


\section{Female spike count-based discrimination (count cells)}

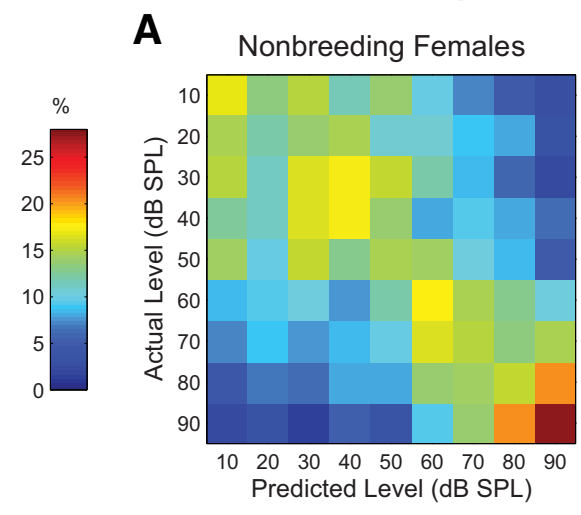

No count cells were recorded from breeding females
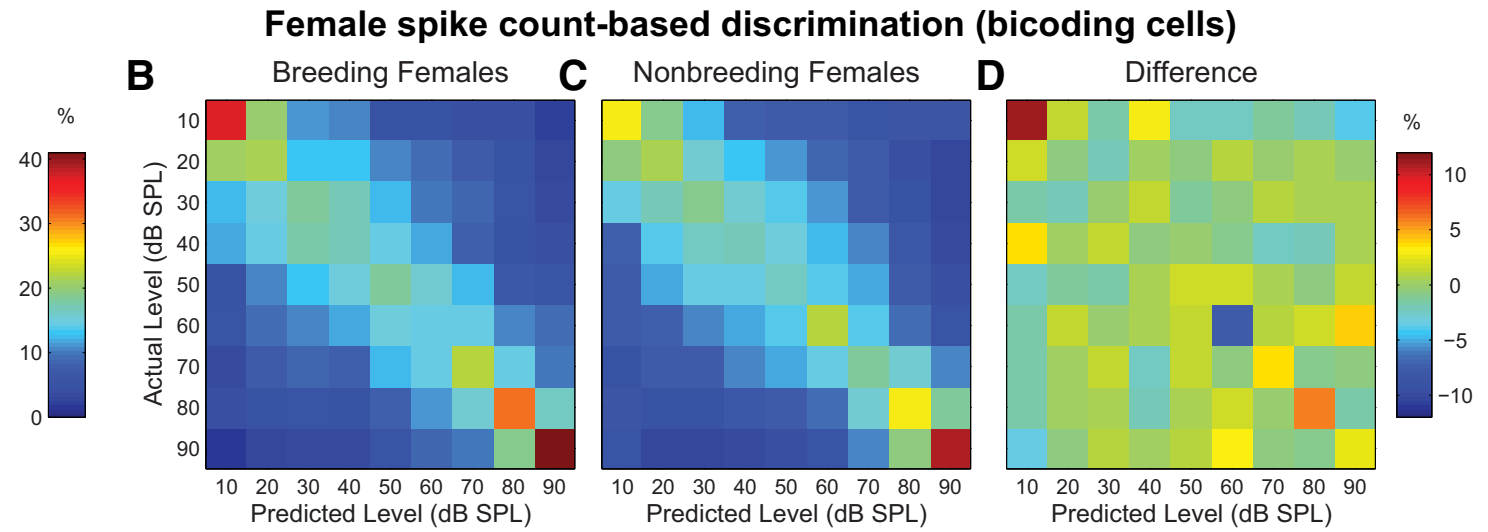

Figure 7. Breeding condition does not affect female spike count-based intensity discrimination. $A$, Spike count-based confusion matrix for count cells from nonbreeding females. Plot conventions are identical to Figure 5 . No count cells were recorded from breeding females, so no between-group comparison could be performed. $B$, Spike count-based confusion matrix for bicoding cells from breeding females. C, Confusion matrix for bicoding cells from nonbreeding females. $\boldsymbol{D}$, Confusion matrix created by subtracting the nonbreeding female matrix in $\boldsymbol{C}$ from the breeding female matrix in $\boldsymbol{B}$. Color scale on the right.

cells from nonbreeding females $\left(t_{(1,26)}, p<0.001\right)$. Together, these results suggest that breeding condition enhances intensity discrimination by increasing the range of discriminable intensities on a cell-by-cell basis.

\section{Breeding condition reduces the optimal temporal resolution for female intensity encoding}

The spike timing-based classification described here was performed after convolving each spike train with a Gaussian curve. The smoothed function generated by this approach mimics the excitatory postsynaptic membrane potential of a hypothetical downstream neuron. Thus, the width of the Gaussian used for this convolution, $\sigma$, determines the temporal window over which the presynaptic neural response can be integrated: small values of $\sigma$ preserve fine temporal structure but may be susceptible to uninformative response jitter. Large values of $\sigma$ reduce noise, but at a cost of reduced temporal resolution.

The spike timing-based discrimination results reported above were calculated at each neuron's optimal $\sigma$. To determine whether breeding state alters the optimal temporal resolution for the discrimination of song intensities, we compared average $\sigma$ values between breeding and nonbreeding condition birds.

A representative response evoked at $90 \mathrm{~dB}$ SPL from a bicoding neuron is shown in Figure 10A. This cell, recorded from a breeding female, has an optimal $\sigma$ of $4 \mathrm{~ms}$. The tight spike timing reliability exhibited by this cell is pronounced when compared with the responses in Figure 10B, which shows the activity of a bicoding neuron at the same intensity
(90 dB SPL) recorded from a nonbreeding female. This nonbreeding cell displayed a more sustained activity profile, and its optimal $\sigma$ was substantially larger $(64 \mathrm{~ms})$ than the breeding cell depicted in Figure 10A.

A two-way ANOVA was performed to determine the effects of breeding condition and cell type (temporal or bicoding) on female optimal $\sigma$ values. As shown in Figure $10 C$, breeding condition significantly reduced the optimal $\sigma\left(F_{(1,70)}=8.75\right.$, $p<0.01)$. This reduction amounts to increasing the temporal resolution by a factor of $\sim 4-5$ (nonbreeding: $63.4 \pm 13.84 \mathrm{~ms}$, breeding: $14.36 \pm 2.96 \mathrm{~ms})$. No effect of cell type $\left(F_{(1,70)}=\right.$ $0.00, p=0.99)$ was observed, nor was there an interaction between cell type and breeding condition $\left(F_{(1,70)}=0.24, p=\right.$ 0.62).

Conversely, breeding condition had no effect on male optimal $\sigma$ (breeding: $43.8 \pm 12.0 \mathrm{~ms}$, nonbreeding: $52.4 \pm 11.72$ $\left.\mathrm{ms} ; F_{(1,63)}=0.48, p=0.49\right)$. Values were similar across cell types $\left(F_{(1,63)}=0.68, p=0.41\right)$, and no condition $\times$ cell type interaction was observed $\left(F_{(1,63)}=0.83, p=0.37\right.$; data not shown).

Together, these results indicate that breeding condition increases the optimal temporal resolution for intensity coding in a sex-specific manner. Furthermore, breeding condition enhances the neural discrimination of song amplitude in a select subset of female neurons (bicoding cells) by increasing the range of discriminable intensities on a cell-by-cell basis. This latter effect is only observed when discrimination is made on the basis of spike timing information. 


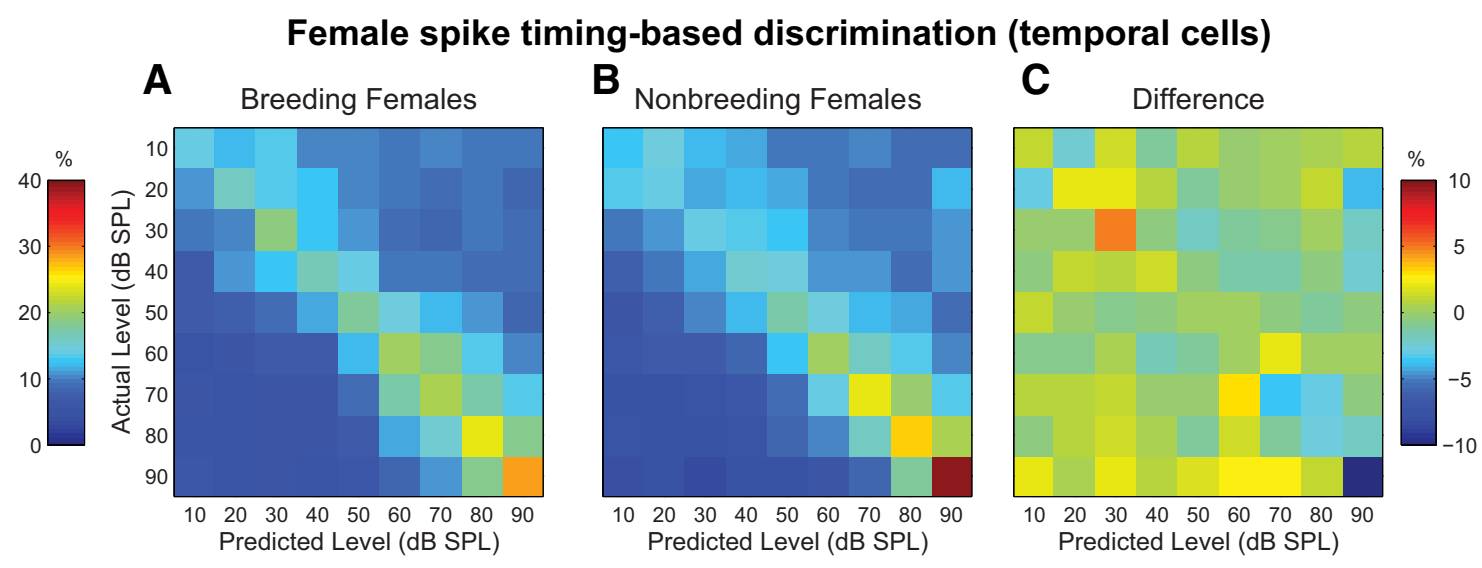

Female spike timing-based discrimination (bicoding cells)
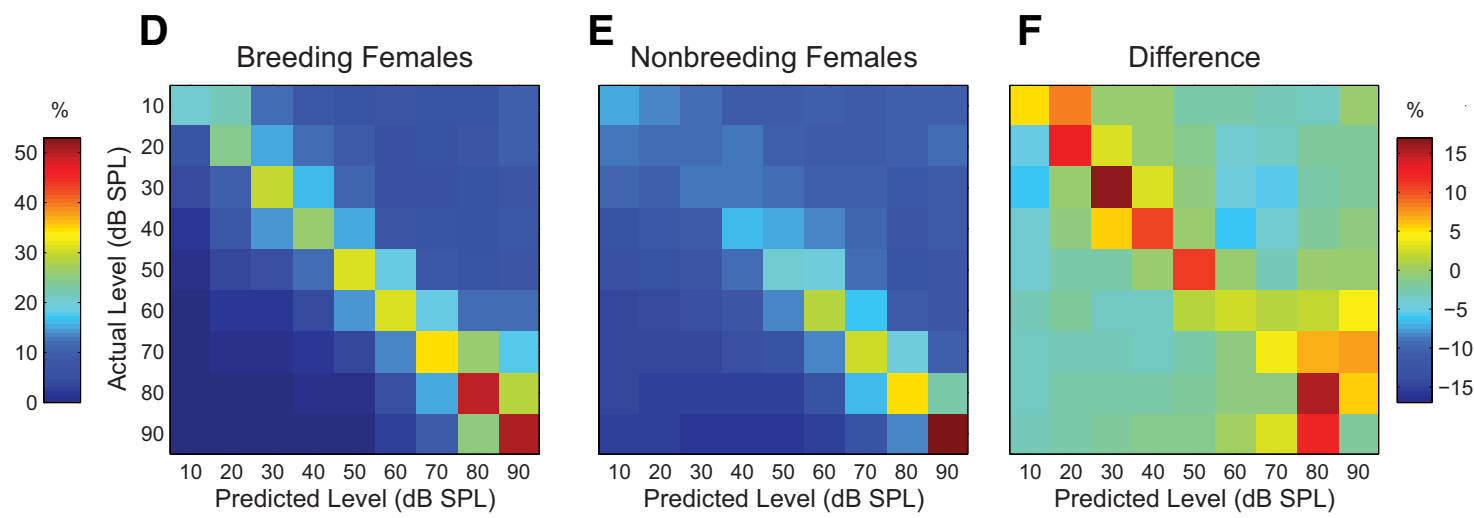

Figure 8. Breeding condition enhancement of female spike timing-based intensity discrimination is cell specific. Plot conventions are identical to Figure 5. $\boldsymbol{A}, \boldsymbol{B}$, Spike timing-based confusion matrices for temporal cells from breeding $(\boldsymbol{A})$ and nonbreeding $(\boldsymbol{B})$ females. Color scale is on the left. $\boldsymbol{C}$, Confusion matrix created by subtracting the nonbreeding female matrix in $\boldsymbol{B}$ from the breeding female matrix in $\boldsymbol{A}$. Color scale is on the right. No effect of breeding condition is observed $\boldsymbol{D}, \boldsymbol{E}$, Spike timing-based confusion matrices for bicoding cells from breeding $(\boldsymbol{D})$ and nonbreeding $(\boldsymbol{E})$ females. Color scale is on the left. $\boldsymbol{F}$, Confusion matrix created by subtracting the nonbreeding female matrix in $\boldsymbol{E}$ from the breeding female matrix in D. Color scale is on the right. Enhanced discrimination accuracy is observed, particularly at low-mid song amplitudes (20-50 dB SPL, represented by four orange-red squares near the top left hand corner).

\section{Discussion}

Spike timing and auditory discrimination

Understanding how spike timing contributes to sensory discrimination is fundamental for linking neural activity with perception. In the auditory nerve and brainstem, spike timing plays an important role in sound encoding (Kiang, 1965; Rose et al., 1967; Young and Sachs, 1979; for review, see Frisina, 2001). Only recently, however, have temporal codes been investigated in the vertebrate telencephalon (for reviews, see Huetz et al., 2011; Gaucher et al., 2013). The majority of these studies have asked how the discrimination of two or more vocalizations depends on the temporal resolution of individual cortical responses (Huetz et al., 2004, 2006, 2009; Narayan et al., 2006; Schnupp et al., 2006; Wang et al., 2007; Billimoria et al., 2008; Engineer et al., 2008; Recanzone, 2008; Russ et al., 2008; Walker et al., 2008; Centanni et al., 2013; Ter-Mikaelian et al., 2013). Overwhelmingly, the data point toward higher discrimination accuracy at shorter time scales; in general, 1-30 ms has been reported as optimal for single-cell temporal integration (Narayan et al., 2006; Schnupp et al., 2006; Engineer et al., 2008; Recanzone, 2008; Russ et al., 2008; Walker et al., 2008; Huetz et al., 2009; Centanni et al., 2013; Ter-Mikaelian et al., 2013).

Here we found that single neurons in the avian forebrain are capable of using spike timing reliability to accurately discriminate the RMS sound level of a complex signal. Furthermore, we report that similar temporal resolutions, $(\sim 10-60 \mathrm{~ms})$, are optimal for the discrimination of sound intensity. Our results support the idea that the contribution of spike timing is not limited to the discrimination of sounds that differ in terms of spectral or temporal properties but also extends to complex sounds whose spectrotemporal features remain constant but vary in mean intensity (Malone et al., 2010).

\section{Identification of functionally distinct cell types}

We found that cells in the avian auditory forebrain segregate into three functionally distinct cell groups. Although we originally identified these cellular clusters on the basis of their intensity discrimination capabilities, we found that they are also well described by their firing rate-song level profiles. Two of these clusters display a marked similarity to data published by Billimoria et al. (2008). These authors recorded extracellular activity from Field L of male zebra finches and assessed how well neurons could discriminate among different conspecific songs across a range of intensities. They identified two classes of neurons: those that demonstrated monotonically increasing firing rates as song intensity increased (which they termed "intensity sensitive" neurons), and those that displayed clear temporal responses but maintained flat rate-level functions across song amplitude (which they termed "intensity invariant" neurons). A compari- 

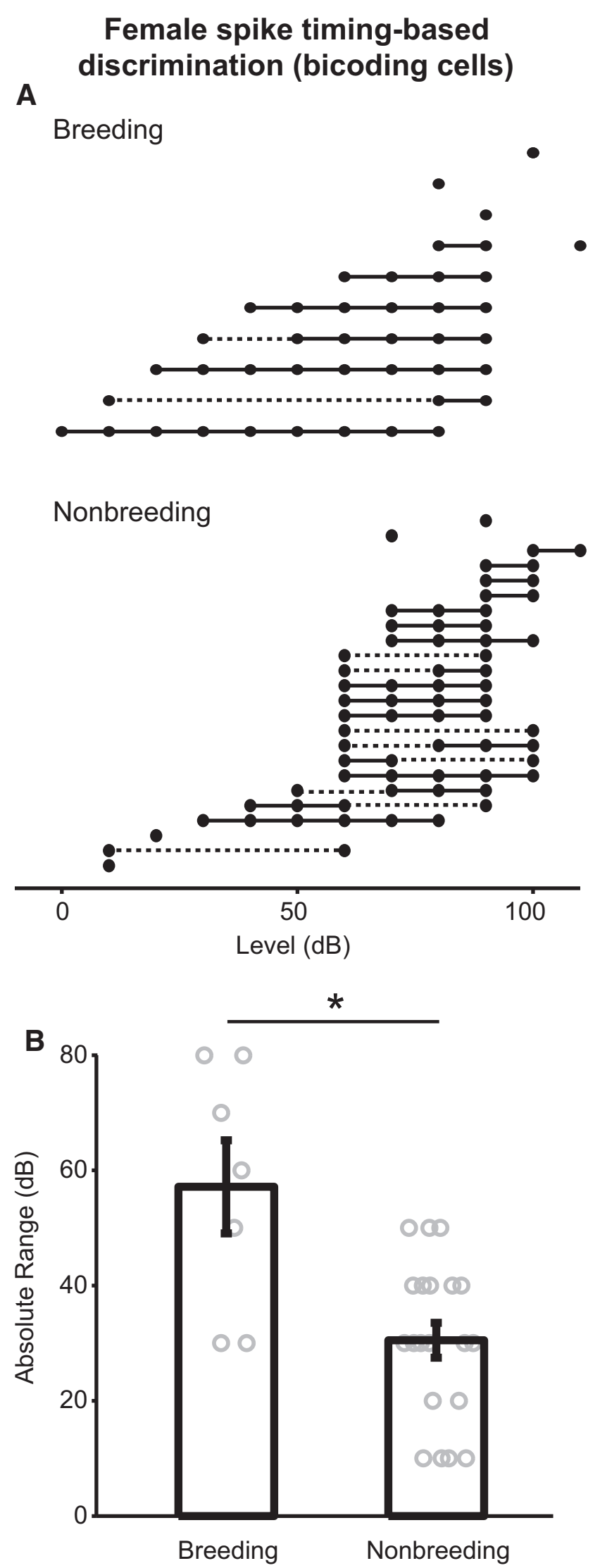

Figure 9. Breeding condition increases the range of song intensities discriminable by female bicoding cells. A, Plot illustrating the range of discriminable intensities for female bicoding cells. Each row represents one neuron. Intensities that are discriminable at a statistically significant level are represented by filled dots (for isolated intensities) and thick solid lines (for a series of son of their work with the present study raises a few points worth mentioning.

First, Billimoria et al. (2008) suggested that their "intensity sensitive" neurons are particularly well suited to convey information about song amplitude. Our results support this notion. Of the three cell classes we describe here, our "bicoding" neurons display the greatest overall accuracy (Fig. 4B). On the basis of their monotonically increasing rate-level profiles (Fig. $4 A$ ), it seems likely that these cells were drawn from the same population as the "intensity sensitive" neurons of Billimoria et al. (2008).

Second, based on their flat rate-level profiles (Fig. 4A), our "temporal" cells are likely the same as the previously mentioned “intensity invariant” neurons (Billimoria et al., 2008). Billimoria et al. (2008) posited that these neurons maintain accurate song representations regardless of sound level. Overall, our results agree with their hypothesis: while these cells are capable of discriminating song intensity on the basis of spike timing information, their discrimination accuracy is significantly lower than the bicoding neurons (Fig. $4 B$ ), and within their response range, their response patterns are not well differentiated (Fig. $3 B$ ). Thus, it is plausible that temporal cells, which make up a majority (54\%) of our sample, primarily serve an important purpose unrelated to intensity discrimination (i.e., stable song encoding across different listening conditions). Notably, while temporal cells constitute approximately half of all cells recorded in Field L, they make up the majority in CM and along the CM/L border. These findings suggest that the neural representation of song identity (or other auditory objects) stabilizes as one moves along the ascending auditory pathway.

Finally, we describe a third group of cells that display suppressed activity as song level increases. These "count" cells, which comprise a minority of our dataset $(8 \%)$, are capable of limited, but significant, intensity discrimination solely on the basis of spike counts. Their precise role in auditory coding remains to be determined.

\section{Androgens and spike timing-based auditory coding}

Given the important role of testosterone in modulating vocal communication, surprisingly little is known about the role of androgens in modulating spike timing-based coding in the central auditory pathway. Huetz et al. (2006) recorded single-unit responses from the sensorimotor region HVC of male canaries that were housed under differing photoperiods and examined the contribution of spike timing in the discrimination of natural and reversed versions of the bird's own song. While their findings highlight an important role for spike timing in the encoding of a bird's own song, no effect of photoperiod was observed. Similarly, we report here that male spike timing-based coding of song intensity is unaffected by breeding condition. These results raise the question of whether male intensity discrimination is relatively insensitive to changes in plasma hormone levels in general, or whether estradiol, which was administered to females in this study, is simply a more effective modulator. Additional studies using a combination of systemic hormonal manipulations, in-

$\leftarrow$

consecutive intensities). Gaps in the range (where intensities are not significantly discriminable) are connected by dashed lines to aid the viewer. (ells are grouped by breeding (top) or nonbreeding (bottom) condition and are arranged in order of the lowest intensity significantly discriminable. $\boldsymbol{B}$, Plot examining the effect of breeding condition on absolute discrimination range of female bicoding cells. Error bars indicate mean \pm SEM. Circles represent individual neurons. ${ }^{*} p<0.05$. 


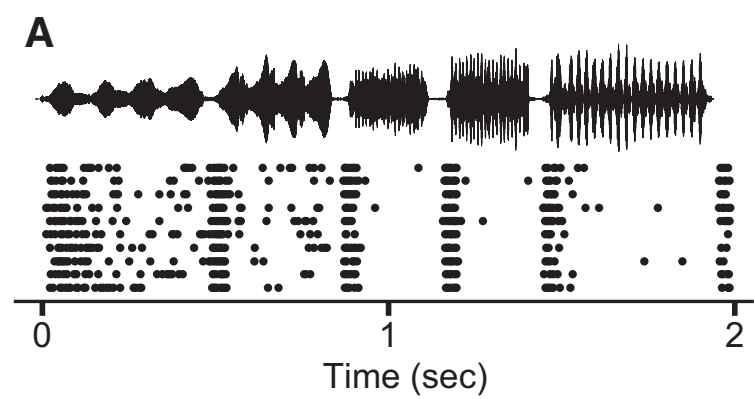

B

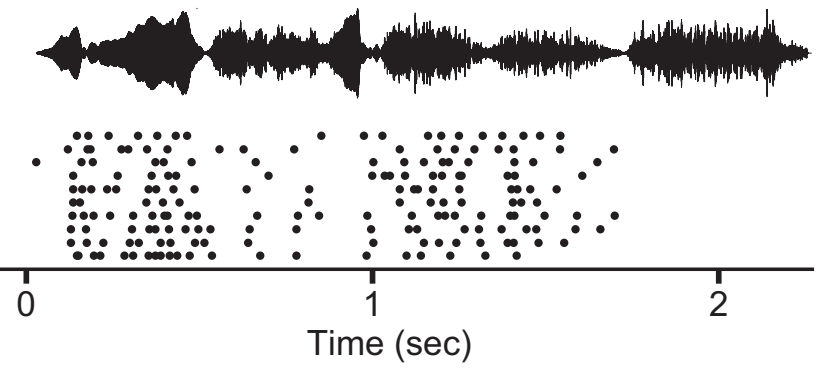

C - Bicoding cells - Temporal cells

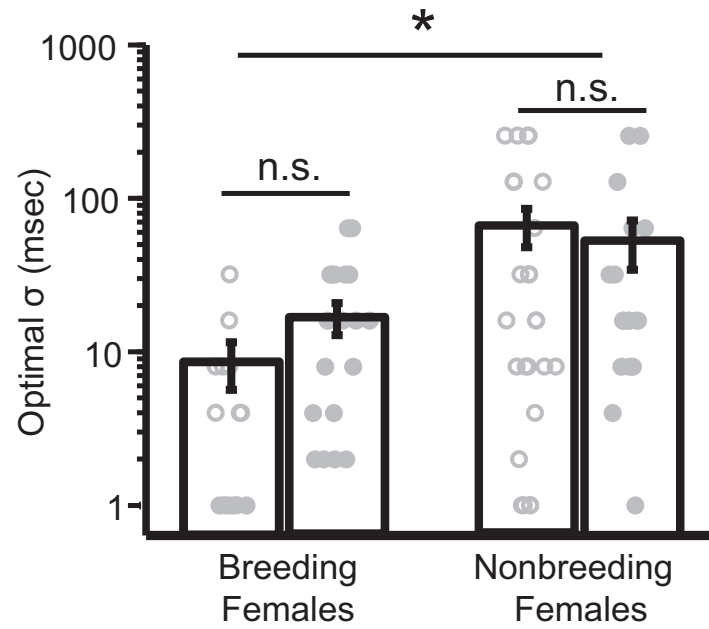

Figure 10. Breeding condition increases the temporal resolution required for optimal spike timing-based intensity discrimination in females. $\boldsymbol{A}, \boldsymbol{B}$, Raster plots from bicoding cells recorded at $90 \mathrm{~dB}$ SPL in a breeding $(\boldsymbol{A})$ and nonbreeding $(\boldsymbol{B})$ female. Song onset is at time 0 . Amplitude envelopes of song stimuli are shown above each panel. $\boldsymbol{A}$, The breeding cell had an optimal $\sigma$ of $4 \mathrm{~ms}$. $\boldsymbol{B}$, The nonbreeding cell had an optimal $\sigma$ of $64 \mathrm{~ms}$. C, Plot examining the effects of breeding condition and cell type on female optimal $\sigma$ values. Error bars indicate mean \pm SEM. Circles represent individual neurons. ${ }^{*} p<0.05$. n.s., Not significant.

cluding nonaromatizable androgens, such as dihydrotestosterone, are needed to distinguish among these possibilities, and to determine whether androgens are capable of modulating auditory coding in females.

\section{Estrogens and spike timing-based auditory coding}

A growing body of literature has highlighted the role of circulating and brain-derived estrogens in modulating auditory perception, evoked potentials, and neuronal activity (for review, see Caras, 2013). The impact of estrogen on spike timing-based au- ditory coding, however, remains poorly understood. To date, only three previous studies have addressed this issue (Huetz et al., 2006; Liu and Schreiner, 2007; Tremere and Pinaud, 2011). Liu and Schreiner (2007) recorded multiunit responses from the auditory cortex of female mice that were either recent mothers or naive regarding pup care. The authors found that when recordings were analyzed with a $2 \mathrm{~ms}$ resolution, the responses of mothers conveyed more information for pup call detection and discrimination compared with responses of naive females. Although interpretation of this finding is limited by the fact that hormone levels were not measured, and the relative role of sex steroids and pup-care experience cannot be separated (Miranda and Liu, 2009), their results indirectly support a possible modulatory role for estrogen in spike timing-based neural discrimination.

Additional evidence is provided by Tremere and Pinaud (2011), who used a linear decoder to analyze the ability of single neurons in the zebra finch caudomedial nidopallium to discriminate among four conspecific songs during manipulation of local estradiol levels. The authors reported that estradiol infusion enhanced discrimination accuracy, and estrogen receptor blockade or aromatase inhibition decreased accuracy, even after normalizing spike trains to account for hormone-dependent changes in evoked activity. Their results suggest that endogenous, brainderived estradiol may enhance song discrimination in part by shaping fine temporal processing.

Our results support and expand on these findings by demonstrating that, in females, breeding condition enhances spike timing-based discrimination accuracy and expands the range of song intensities that are neurally discriminable by bicoding neurons. Additionally, we observed that breeding condition reduces the temporal window required for optimal intensity discrimination. Finally, we found a seasonal shift in the cellular distribution, such that bicoding cells constituted the majority of the cells in nonbreeding females, whereas temporal cells made up more than two-thirds of neurons in breeding females. Based on the putative functional roles for the different cell types (discussed above), it seems reasonable to hypothesize that estrogen acts on bicoding cells to enhance intensity discrimination during the reproductive period, whereas the increased proportion of temporal cells allows for a stable representation of signal identity across seasons.

We presented a similar hypothesis to explain the selective effect of estradiol on sound-evoked firing rates of Field L neurons (Caras et al., 2012). In this study, estradiol specifically affected the activity of neurons with monotonic pure-tone rate-level functions while leaving nonmonotonic neurons unaffected. An obvious question that arises from our present findings was whether the estrogen-targeted cells in Caras et al. (2012) and the current study are identical. It appears that this is not the case: monotonic and nonmonotonic tone responses can be found in approximately equal proportions in bicoding and temporal cell populations (data not shown).

Collectively, these findings suggest that, in addition to increasing neural discharge rates and sensitivity (Caras, 2013), estrogens shape single-unit responses at a high temporal resolution to enhance the discrimination of vocal stimuli and optimize avian vocal communication under different breeding conditions. Similar strategies may be used by other vertebrate taxa to optimize the recognition of mates during periods of reproductive readiness or the recognition of offspring calls during periods of maternal caregiving. 


\section{References}

Akçay Ç, Tom ME, Holmes D, Campbell SE, Beecher MD (2011) Sing softly and carry a big stick: signals of aggressive intent in the song sparrow. Anim Behav 82:377-382. CrossRef

Arak A (1983) Sexual selection by male-male competition in natterjack toad choruses. Nature 306:261-262. CrossRef

Arak A (1988) Female mate selection in the natterjack toad: active choice or passive attraction? Behav Ecol Sociobiol 22:317-327.

Avey MT, Phillmore LS, MacDougall-Shackleton SA (2005) Immediate early gene expression following exposure to acoustic and visual components of courtship in zebra finches. Behav Brain Res 165:247-253. CrossRef Medline

Bakin JS, Weinberger NM (1990) Classical conditioning induces CSspecific receptive field plasticity in the auditory cortex of the guinea pig. Brain Res 536:271-286. CrossRef Medline

Bass AH (2008) Steroid-dependent plasticity of vocal motor systems: novel insights from teleost fish. Brain Res Rev 57:299-308. CrossRef Medline

Billimoria CP, Kraus BJ, Narayan R, Maddox RK, Sen K (2008) Invariance and sensitivity to intensity in neural discrimination of natural sounds. J Neurosci 28:6304-6308. CrossRef Medline

Brackenbury JH (1979) Power capabilities of the avian sound-producing system. J Exp Biol 78:163-166.

Brenowitz EA (1982) The active space of red-winged blackbird song. J Comp Physiol A Neuroethol Sens Neural Behav Physiol 147:511-522. CrossRef

Brenowitz EA (2008) Plasticity of the song control system in adult birds. In: Neuroscience of birdsong (Zeigler P, Marler P, eds), p 332. New York: Cambridge UP.

Caras ML (2013) Estrogenic modulation of auditory processing: a vertebrate comparison. Front Neuroendocrinol 34:285-299. CrossRef Medline

Caras ML, Brenowitz E, Rubel EW (2010) Peripheral auditory processing changes seasonally in Gambel's white-crowned sparrow. J Comp Physiol A Neuroethol Sens Neural Behav Physiol 196:581-599. CrossRef Medline

Caras ML, O’Brien M, Brenowitz EA, Rubel EW (2012) Estradiol selectively enhances auditory function in avian forebrain neurons. J Neurosci 32: 17597-17611. CrossRef Medline

Cardin JA, Schmidt MF (2003) Song system auditory responses are stable and highly tuned during sedation, rapidly modulated and unselective during wakefulness, and suppressed by arousal. J Neurophysiol 90:28842899. CrossRef Medline

Centanni TM, Engineer CT, Kilgard MP (2013) Cortical speech-evoked response patterns in multiple auditory fields are correlated with behavioral discrimination ability. J Neurophysiol 110:177-189. CrossRef Medline

Cynx J, Williams H, Nottebohm F (1992) Hemispheric differences in avian song discrimination. Proc Natl Acad Sci U S A 89:1372-1375. CrossRef Medline

Dave AS, Yu AC, Margoliash D (1998) Behavioral state modulation of auditory activity in a vocal motor system. Science 282:2250-2254. CrossRef Medline

Del Negro C, Edeline JM (2002) Sex and season influence the proportion of thin spike cells in the canary HVc. Neuroreport 13:2005-2009. CrossRef Medline

Del Negro C, Lehongre K, Edeline JM (2005) Selectivity of canary HVC neurons for the bird's own song: modulation by photoperiodic conditions. J Neurosci 25:4952-4963. CrossRef Medline

Eggermont JJ (1998) Is there a neural code? Neurosci Biobehav Rev 22:355370. CrossRef Medline

Engineer CT, Perez CA, Chen YH, Carraway RS, Reed AC, Shetake JA, Jakkamsetti V, Chang KQ, Kilgard MP (2008) Cortical activity patterns predict speech discrimination ability. Nat Neurosci 11:603-608. CrossRef Medline

Fellers GM (1979) Aggression, territoriality, and mating behaviour in North American treefrogs. Anim Behav 27:107-119. CrossRef

Frisina RD (2001) Subcortical neural coding mechanisms for auditory temporal processing. Hear Res 158:1-27. CrossRef Medline

Fritz J, Shamma S, Elhilali M, Klein D (2003) Rapid task-related plasticity of spectrotemporal receptive fields in primary auditory cortex. Nat Neurosci 6:1216-1223. CrossRef Medline

Fritz JB, Elhilali M, Shamma SA (2005) Differential dynamic plasticity of A1 receptive fields during multiple spectral tasks. J Neurosci 25:7623-7635. CrossRef Medline

Gaucher Q, Huetz C, Gourévitch B, Laudanski J, Occelli F, Edeline JM (2013) How do auditory cortex neurons represent communication sounds? Hear Res 305:102-112. CrossRef Medline
George I, Vernier B, Richard JP, Hausberger M, Cousillas H (2004) Hemispheric specialization in the primary auditory area of awake and anesthetized starlings (Sturnus vulgaris). Behav Neurosci 118:597-610. CrossRef Medline

George I, Cousillas H, Richard JP, Hausberger M (2005) State-dependent hemispheric specialization in the songbird brain. J Comp Neurol 488:48-60. CrossRef Medline

Gerhardt HC (1987) Evolutionary and neurobiological implications of selective phonotaxis in the green treefrog, Hyla cinerea. Anim Behav 35: 1479-1489. CrossRef

Grace JA, Amin N, Singh NC, Theunissen FE (2003) Selectivity for conspecific song in the zebra finch auditory forebrain. J Neurophysiol 89:472487. CrossRef Medline

Hauber ME, Cassey P, Woolley SM, Theunissen FE (2007) Neurophysiological response selectivity for conspecific songs over synthetic sounds in the auditory forebrain of non-singing female songbirds. J Comp Physiol A Neuroethol Sens Neural Behav Physiol 193:765-774. CrossRef Medline

Hillery CM (1984) Seasonality of two midbrain auditory responses in the treefrog, Hyla chrysoscelis. Copeia:844-852.

Hof D, Hazlett N (2010) Low-amplitude song predicts attack in a North American wood warbler. Anim Behav 80:821-828. CrossRef

Holmstrom LA, Eeuwes LB, Roberts PD, Portfors CV (2010) Efficient encoding of vocalizations in the auditory midbrain. J Neurosci 30:802-819. CrossRef Medline

Huetz C, Del Negro C, Lehongre K, Tarroux P, Edeline JM (2004) The selectivity of canary HVC neurons for the Bird's Own Song: rate coding, temporal coding, or both? J Physiol Paris 98:395-406. CrossRef Medline

Huetz C, Del Negro C, Lebas N, Tarroux P, Edeline JM (2006) Contribution of spike timing to the information transmitted by HVC neurons. Eur J Neurosci 24:1091-1108. CrossRef Medline

Huetz C, Philibert B, Edeline JM (2009) A spike-timing code for discriminating conspecific vocalizations in the thalamocortical system of anesthetized and awake guinea pigs. J Neurosci 29:334-350. CrossRef Medline

Huetz C, Gourévitch B, Edeline JM (2011) Neural codes in the thalamocortical auditory system: from artificial stimuli to communication sounds. Hear Res 271:147-158. CrossRef Medline

Kayser C, Logothetis NK, Panzeri S (2010) Millisecond encoding precision of auditory cortex neurons. Proc Natl Acad Sci U S A 107:16976-16981. CrossRef Medline

Kiang NY (1965) Discharge patterns of single fibers in the cat's auditory nerve. Cambridge, MA: Massachusetts Institute of Technology.

Kim G, Doupe A (2011) Organized representation of spectrotemporal features in songbird auditory forebrain. J Neurosci 31:16977-16990. CrossRef Medline

Liu RC, Schreiner CE (2007) Auditory cortical detection and discrimination correlates with communicative significance. PLoS Biol 5:e173. CrossRef Medline

Machens CK, Schütze H, Franz A, Kolesnikova O, Stemmler MB, Ronacher B, Herz AV (2003) Single auditory neurons rapidly discriminate conspecific communication signals. Nat Neurosci 6:341-342. CrossRef Medline

Malone BJ, Scott BH, Semple MN (2010) Temporal codes for amplitude contrast in auditory cortex. J Neurosci 30:767-784. CrossRef Medline

Maruska KP, Ung US, Fernald RD (2012) The African cichlid fish Astatotilapia burtoni uses acoustic communication for reproduction: sound production, hearing, and behavioral significance. PLoS One 7:e37612. CrossRef Medline

Meitzen J, Perkel DJ, Brenowitz EA (2007a) Seasonal changes in intrinsic electrophysiological activity of song control neurons in wild song sparrows. J Comp Physiol A Neuroethol Sens Neural Behav Physiol 193:677683. CrossRef Medline

Meitzen J, Moore IT, Lent K, Brenowitz EA, Perkel DJ (2007b) Steroid hormones act transsynaptically within the forebrain to regulate neuronal phenotype and song stereotypy. J Neurosci 27:12045-12057. CrossRef Medline

Meitzen J, Weaver AL, Brenowitz EA, Perkel DJ (2009a) Plastic and stable electrophysiological properties of adult avian forebrain song-control neurons across changing breeding conditions. J Neurosci 29:6558-6567. CrossRef Medline

Meitzen J, Thompson CK, Choi H, Perkel DJ, Brenowitz EA (2009b) Time course of changes in Gambel's white-crowned sparrow song behavior following transitions in breeding condition. Horm Behav 55:217-227. CrossRef Medline

Mesgarani N, David SV, Fritz JB, Shamma SA (2008) Phoneme representa- 
tion and classification in primary auditory cortex. J Acoust Soc Am 123: 899-909. CrossRef Medline

Middleton J (1965) Testicular responses of house sparrows and whitecrowned sparrows to short daily photoperiods with low intensities of light. Physiol Zool 38:255-266.

Miranda JA, Liu RC (2009) Dissecting natural sensory plasticity: hormones and experience in a maternal context. Hear Res 252:21-28. CrossRef Medline

Nagel KI, Doupe AJ (2008) Organizing principles of spectro-temporal encoding in the avian primary auditory area Field L. Neuron 58:938-955. CrossRef Medline

Narayan R, Graña G, Sen K (2006) Distinct time scales in cortical discrimination of natural sounds in songbirds. J Neurophysiol 96:252-258. CrossRef Medline

Nemeth E (2004) Measuring the sound pressure level of the song of the Screaming Piha Lipaugus vociferans: one of the loudest birds in the world. Bioacoustics 14:225-228. CrossRef

Niwa M, Johnson JS, O'Connor KN, Sutter ML (2012) Active engagement improves primary auditory cortical neurons' ability to discriminate temporal modulation. J Neurosci 32:9323-9334. CrossRef Medline

Park KH, Meitzen J, Moore IT, Brenowitz EA, Perkel DJ (2005) Seasonallike plasticity of spontaneous firing rate in a songbird pre-motor nucleus. J Neurobiol 64:181-191. CrossRef Medline

Phan ML, Vicario DS (2010) Hemispheric differences in processing of vocalizations depend on early experience. Proc Natl Acad Sci U S A 107: 2301-2306. CrossRef Medline

Pinaud R, Tremere LA (2012) Control of central auditory processing by a braingenerated oestrogen. Nat Rev Neurosci 13:521-527. CrossRef Medline

Poirier C, Boumans T, Verhoye M, Balthazart J, Van der Linden A (2009) Own-song recognition in the songbird auditory pathway: selectivity and lateralization. J Neurosci 29:2252-2258. CrossRef Medline

Polley DB, Steinberg EE, Merzenich MM (2006) Perceptual learning directs auditory cortical map reorganization through top-down influences. J Neurosci 26:4970-4982. CrossRef Medline

Recanzone GH (2008) Representation of con-specific vocalizations in the core and belt areas of the auditory cortex in the alert macaque monkey. J Neurosci 28:13184-13193. CrossRef Medline

Recanzone GH, Schreiner CE, Merzenich MM (1993) Plasticity in the frequency representation of primary auditory cortex following discrimination training in adult owl monkeys. J Neurosci 13:87-103. Medline

Remage-Healey L, Joshi NR (2012) Changing neuroestrogens within the auditory forebrain rapidly transform stimulus selectivity in a downstream sensorimotor nucleus. J Neurosci 32:8231-8241. CrossRef Medline

Remage-Healey L, Coleman MJ, Oyama RK, Schlinger BA (2010) Brain estrogens rapidly strengthen auditory encoding and guide song preference in a songbird. Proc Natl Acad Sci U S A 107:3852-3857. CrossRef Medline

Remage-Healey L, Dong SM, Chao A, Schlinger BA (2012) Sex-specific, rapid neuroestrogen fluctuations and neurophysiological actions in the songbird auditory forebrain. J Neurophysiol 107:1621-1631. CrossRef Medline

Remage-Healey L, Jeon SD, Joshi NR (2013) Recent evidence for rapid synthesis and action of oestrogens during auditory processing in a songbird. J Neuroendocrinol 25:1024-1031. CrossRef Medline

Riters LV, Baillien M, Eens M, Pinxten R, Foidart A, Ball GF, Balthazart J (2001) Seasonal variation in androgen-metabolizing enzymes in the diencephalon and telencephalon of the male European starling (Sturnus vulgaris). J Neuroendocrinol 13:985-997. CrossRef Medline

Rohmann KN, Bass AH (2011) Seasonal plasticity of auditory hair cell frequency sensitivity correlates with plasma steroid levels in vocal fish. J Exp Biol 214:1931-1942. CrossRef Medline

Rose JE, Brugge JF, Anderson DJ, Hind JE (1967) Phase-locked response to low-frequency tones in single auditory nerve fibers of the squirrel monkey. J Neurophysiol 30:769-793. Medline

Russ BE, Ackelson AL, Baker AE, Cohen YE (2008) Coding of auditorystimulus identity in the auditory non-spatial processing stream. J Neurophysiol 99:87-95. Medline

Schnupp JW, Hall TM, Kokelaar RF, Ahmed B (2006) Plasticity of temporal pattern codes for vocalization stimuli in primary auditory cortex. J Neurosci 26:4785-4795. CrossRef Medline

Schreiber S, Fellous JM, Whitmer D, Tiesinga P, Sejnowski TJ (2003) A new correlation-based measure of spike timing reliability. Neurocomputing 52:925-931. CrossRef Medline

Searcy WA (1996) Sound-pressure levels and song preferences in female
Red-winged Blackbirds (Agelaius phoeniceus) (Aves, Emberizidae). Ethology 102:187-196.

Searcy WA, Beecher MD (2009) Song as an aggressive signal in songbirds. Anim Behav 78:1281-1292. CrossRef

Sen K, Theunissen FE, Doupe AJ (2001) Feature analysis of natural sounds in the songbird auditory forebrain. J Neurophysiol 86:1445-1458. Medline

Sisneros JA (2009) Steroid-dependent auditory plasticity for the enhancement of acoustic communication: recent insights from a vocal teleost fish. Hear Res 252:9-14. CrossRef Medline

Sisneros JA, Bass AH (2003) Seasonal plasticity of peripheral auditory frequency sensitivity. J Neurosci 23:1049-1058. Medline

Sisneros JA, Forlano PM, Deitcher DL, Bass AH (2004) Steroid-dependent auditory plasticity leads to adaptive coupling of sender and receiver. Science 305:404-407. CrossRef Medline

Smith GT, Brenowitz EA, Wingfield JC, Baptista LF (1995) Seasonal changes in song nuclei and song behavior in Gambel's white-crowned sparrows. J Neurobiol 28:114-125. CrossRef Medline

Smith GT, Brenowitz EA, Beecher MD, Wingfield JC (1997) Seasonal changes in testosterone, neural attributes of song control nuclei and song structure in wild songbirds. J Neurosci 17:6001-6010. Medline

Soma KK, Hartman VN, Wingfield JC, Brenowitz EA (1999) Seasonal changes in androgen receptor immunoreactivity in the song nucleus $\mathrm{HVC}$ of a wild bird. J Comp Neurol 409:224-236. CrossRef Medline

Ter-Mikaelian M, Semple MN, Sanes DH (2013) Effects of spectral and temporal disruption on cortical encoding of gerbil vocalizations. J Neurophysiol 110:1190-1204. CrossRef Medline

Theunissen F, Miller JP (1995) Temporal encoding in nervous systems: a rigorous definition. J Comput Neurosci 2:149-162. CrossRef Medline

Tramontin AD, Hartman VN, Brenowitz EA (2000) Breeding conditions induce rapid and sequential growth in adult avian song control circuits: a model of seasonal plasticity in the brain. J Neurosci 20:854-861. Medline

Tramontin AD, Wingfield JC, Brenowitz EA (2003) Androgens and estrogens induce seasonal-like growth of song nuclei in the adult songbird brain. J Neurobiol 57:130-140. CrossRef Medline

Tremere LA, Pinaud R (2011) Brain-generated estradiol drives long-term optimization of auditory coding to enhance the discrimination of communication signals. J Neurosci 31:3271-3289. CrossRef Medline

Tremere LA, Jeong JK, Pinaud R (2009) Estradiol shapes auditory processing in the adult brain by regulating inhibitory transmission and plasticityassociated gene expression. J Neurosci 29:5949-5963. CrossRef Medline

Tremere LA, Kovaleski RF, Burrows K, Jeong JK, Pinaud R (2012) Mechanistic basis and functional roles of long-term plasticity in auditory neurons induced by a brain-generated estrogen. J Neurosci 32:16478-16495. CrossRef Medline

Walker KM, Ahmed B, Schnupp JW (2008) Linking cortical spike pattern codes to auditory perception. J Cogn Neurosci 20:135-152. CrossRef Medline

Walkowiak W (1980) The coding of auditory signals in the torus semicircularis of the fire-bellied toad and the grass frog: responses to simple stimuli and to conspecific calls. J Comp Physiol A Neuroethol Sens Neural Behav Physiol 138:131-148. CrossRef

Wang L, Narayan R, Graña G, Shamir M, Sen K (2007) Cortical discrimination of complex natural stimuli: can single neurons match behavior? J Neurosci 27:582-589. CrossRef Medline

Wingfield JC, Farner DS (1978) The annual cycle of plasma irLH and steroid hormones in feral populations of the white-crowned sparrow, Zonotrichia leucophrys gambelii. Biol Reprod 19:1046-1056. CrossRef Medline

Wingfield JC, Crim JW, Mattocks PW Jr, Farner DS (1979) Responses of photosensitive and photorefractory male white-crowned sparrows (Zonotrichia leucophrys gambelii) to synthetic mammalian luteinizing hormone releasing hormone (syn-LHRH). Biol Reprod 21:801-806. CrossRef Medline

Woolley SM, Portfors CV (2013) Conserved mechanisms of vocalization coding in mammalian and songbird auditory midbrain. Hear Res 305:45-56. CrossRef Medline

Yin P, Fritz JB, Shamma SA (2014) Rapid spectrotemporal plasticity in primary auditory cortex during behavior. J Neurosci 34:4396-4408. CrossRef Medline

Young ED, Sachs MB (1979) Representation of steady-state vowels in the temporal aspects of the discharge patterns of populations of auditory nerve fibers. J Acoust Soc Am 66:1381-1403. CrossRef Medline 